\title{
New approach to synthesis of nitronyl and imino nitroxides based on $\mathrm{S}_{\mathrm{N}}{ }^{\mathrm{H}}$ methodology
}

\author{
Evgeny V. Tretyakov, ${ }^{\text {** Irina A. Utepova, }}{ }^{\mathrm{b}}$ Mikhail V. Varaksin, ${ }^{\mathrm{b}}$ Svyatoslav E. Tolstikov, \\ Galina V. Romanenko, ${ }^{\text {a }}$ Artem S. Bogomyakov, ${ }^{\text {a Dmitry V. Stass, }}{ }^{\mathrm{c}}$ Victor I. Ovcharenko, \\ and Oleg N. Chupakhin ${ }^{\text {b,d }}$ \\ ${ }^{a}$ International Tomography Center, Siberian Branch of the Russian Academy of Sciences, \\ 3 a Institutskaya str., 630090 Novosibirsk, Russian Federation \\ ${ }^{b}$ Department of Organic Chemistry, Ural Federal University, 19 Mira str., \\ Ekaterinburg, 620002, Russian Federation \\ ${ }^{c}$ Institute of Chemical Kinetics and Combustion, Siberian Branch of the Russian Academy of \\ Sciences, 3 Institutskaya str., 630090, Novosibirsk, Russian Federation \\ ${ }^{d}$ Institute of Organic Synthesis, Ural Branch of the Russian Academy of Sciences, \\ 20 S. Kovalevskoy str., Ekaterinburg, 620990, Russian Federation \\ E-mail:tev@tomo.nsc.ru
}

\section{Dedicated to Professor Usein M. Dzhemilev on the occasion of his $65^{\text {th }}$ birthday}

\begin{abstract}
It is shown that $\mathrm{S}_{\mathrm{N}}{ }^{\mathrm{H}}$ approach opens new possibilities in the synthesis of polyfunctional nitronyl and imino nitroxides. It is found that the interaction of 4,4,5,5-tetramethyl-4,5-dihydro- $1 \mathrm{H}$ imidazol-3-oxide-1-oxyl lithium salt Li1 with 3,6-diaryl-1,2,4-triazines leads to formation of the corresponding triazines bearing nitronyl nitroxide or imino nitroxide substituent at position 5 of the heterocycle. The reaction of Li1 with pyridazine- $N$-oxide gives rise to nitroxide with buten3-ynyl substituent 5. Spin-labeled 5 could be readily transformed by the use of 1,3-dipolar and nucleophilic addition reactions, as well as oxidative coupling, that gives a large group of new paramagnets: 2-(1H-pyrazol-5-yl)vinyl-, 2-ethynylcyclopropyl-, 2-(3-(ethoxycarbonyl) isoxazol5-yl)vinyl-, 1-(pyrrolidin-1-yl)but-3-ynyl-substituted nitronyl nitroxide and a diradical - 2,2'((1E,7E)-octa-1,7-dien-3,5-diyne-1,8-diyl)bis(4,4,5,5-tetramethyl-4,5-dihydro-1 $H$-imidazol-3oxide-1-oxyl). The new nitroxides were characterized by X-ray single crystal data, ESR and static magnetic susceptibility measurements.
\end{abstract}

Keywords: Nitronyl nitroxides, imino nitroxides, $\mathrm{S}_{\mathrm{N}}{ }^{\mathrm{H}}$ reactions, X-ray diffraction study, ESR spectra 


\section{Introduction}

The increasing application of polyfunctional nitronyl nitroxides $(\mathrm{NNs})^{1}$ in the field of molecular magnetism stimulates the development of the chemistry of these compounds. ${ }^{2}$ The latter includes developing new methods for the targeted synthesis of kinetically stable NNs and methods for their isolation in the form of individual phases, as well as searching for new and general approaches to the synthesis of polyfunctional NNs. A possible pathway involves using a certain synthone that preserves the paramagnetic fragment. NN H1 is such a candidate synthone. Under the action of $\mathrm{KOBu}^{\mathrm{t}}, \mathrm{LiNPr}_{2}^{\mathrm{i}}$, or $\mathrm{LiN}\left(\mathrm{SiMe}_{3}\right)_{2}$ it forms stable paramagnetic organometallic derivatives $M 1\left\{\mathrm{p} K_{\mathrm{a}}(\mathbf{H 1}) \approx 21.9^{3}\right\}$, which upon further reaction with electrophilic reagents yield the products of $C(2)$-functionalization. ${ }^{4}$

In the course of our study of nucleophilic substitution of hydrogen atom in $\pi$-deficient azine$\mathrm{N}$-oxides under the action of organolithium derivative Li1 we found an efficient method for production of hetaryl-substituted NNs based on $\mathrm{S}_{\mathrm{N}}{ }^{\mathrm{H}}$ methodology (Scheme 1). ${ }^{5}$

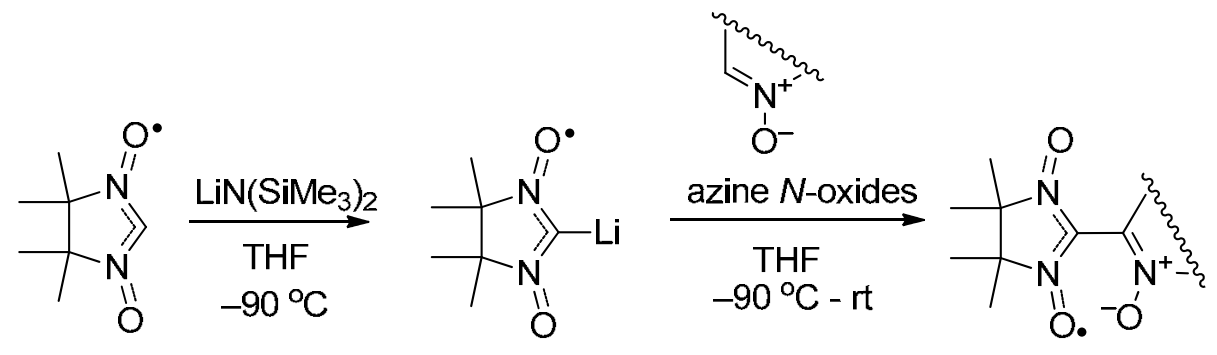

H1

Li1

\section{Scheme 1}

We note that in the reaction of different azine- $N$-oxides (pyridine- $N$-oxide, 2,2'-bipyridyl- $N$ oxide, quinoline- $N$-oxide, isoquinoline- $N$-oxide, phthalazine- $N$-oxide, pyrazine- $N$-oxide, quinoxaline- $N$-oxide, quinoxaline-1,4-dioxide, 3,6-diphenyl-1,2,4-triazine-4-oxide) the $N$-oxide group was preserved in the aromatization of the intermediate $\sigma^{\mathrm{H}}$-adducts. These reactions were the first examples of a new general strategy for the synthesis of NNs. This work seeks new approaches to the synthesis of hitherto inaccessible polyfunctional NNs using Li1 as the starting compound.

\section{Results and Discussion}

\section{Syntheses}

According to generally accepted views the $\mathrm{S}_{\mathrm{N}}{ }^{\mathrm{H}}$ reactions occur in two stages. ${ }^{6}$ At the first stage a nucleophilic fragment adds to a compound having electron-withdrawing substituents forming a $\sigma^{\mathrm{H}}$-adduct, and at the second stage these intermediates aromatize into the corresponding $\mathrm{S}_{\mathrm{N}}{ }^{\mathrm{H}}$ 
products. Two types or aromatization exist, viz., oxidative and eliminative, thus leading to two types of $\mathrm{S}_{\mathrm{N}}{ }^{\mathrm{H}}$ reactions: $\mathrm{S}_{\mathrm{N}}{ }^{\mathrm{H}}(\mathrm{AO})$ and $\mathrm{S}_{\mathrm{N}}{ }^{\mathrm{H}}(\mathrm{AE})$. The first process requires an oxidizing reagent. The elimination-type aromatization requires the presence of an auxiliary group with propensity to anionic stabilization in the (hetero)aromatic substrate or in the nucleophilic moiety ("vicarious" nucleophilic substitution ${ }^{7}$ ).

We found that interaction of highly electrophilic derivatives of 1,2,4-triazine (3,6-diphenyl1,2,4-triazine 2a or 3-(4-ethylphenyl)-6-phenyl-1,2,4-triazine $\mathbf{2 b}$ ) with Li1 results in formation of the products of $\mathrm{S}_{\mathrm{N}}{ }^{\mathrm{H}}$ reactions $3 \mathbf{a}$ and $\mathbf{4 a}$ or $\mathbf{3 b}$ and $\mathbf{4 b}$, respectively, as the main products (Scheme 2). Formation of imino nitroxides $4 \mathbf{a}, \mathbf{b}$ demonstrates that the presence of the nitronyl nitroxide group steers the aromatization of the $\sigma^{\mathrm{H}}$ adducts into the eliminative route. It is important that in this case the auxiliary group is in the nucleophilic moiety.

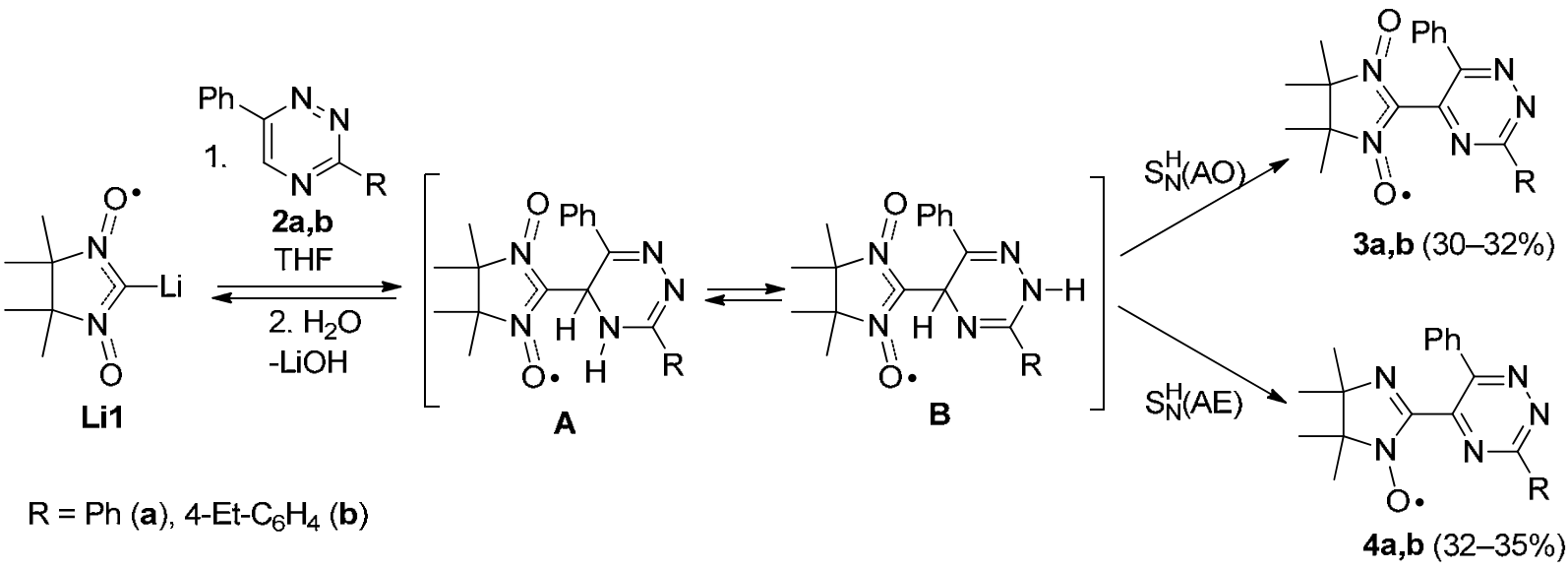

\section{Scheme 2}

The possibility of the discussed reactions involving azines was far from obvious, as the nucleophilicity of the carbanionic center in Li1 is substantially reduced. This is the most likely reason for the failure to perform the reaction of Li1 with mono- (quinoline) and diazines (quinoxaline, pyrimidine) to obtain the corresponding hetaryl-substituted NNs. In these cases only the initial $\mathbf{H 1}$ and the known diradical 1-1 could be isolated from the reaction mixture.

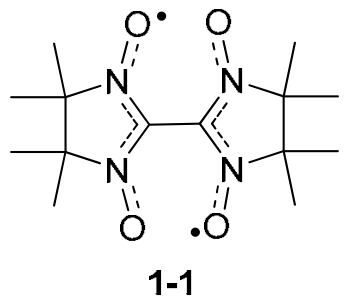

When using pyridazine- $N$-oxide as the electrophilic reagent in these transformations 2imidazoline-3-oxide-1-oxyl containing in its structure a butenynyl substituent was obtained. 
Pyridazine- $N$-oxide reacts with Li1 in THF at $-78{ }^{\circ} \mathrm{C}$ with formation, from XRD data, of exclusively $E$-isomer 5 in $68 \%$ yield. The enyne-substituted NN 5 is a "stable" at ambient conditions dark-blue crystalline solid that decomposes only upon heating to $\sim 94-98{ }^{\circ} \mathrm{C}$ (Scheme 3 ). It should be noted that the works of Okusa et al. ${ }^{8}$ and Igeta et al. ${ }^{9}$ describe the opening of the pyridazine cycle in $\mathrm{N}$-oxide under the action of Grignard reagents ( $\mathrm{ArMgBr}$ ), where the reactions also proceed mostly with formation of 1-arylbut-1-en-3-ynes.

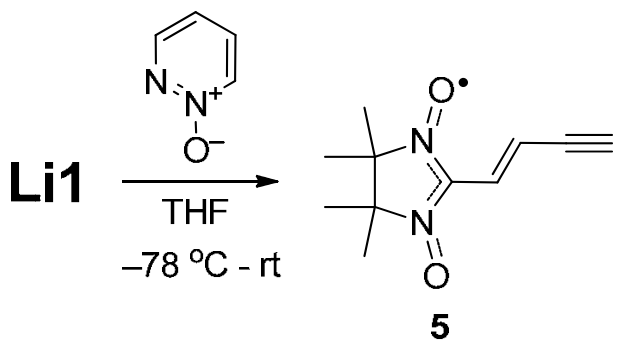

\section{Scheme 3}

With the development of an efficient method for production of 5 bearing reactive synergistic groups the latter could be used as the basic paramagnetic building block for production of new NNs. Let us first consider the reactions of 1,3-dipolar cycloaddition. It was found that 5 slowly reacts with $\mathrm{CH}_{2} \mathrm{~N}_{2}$ in ether to form a mixture of two main products, pyrazolylvinyl-substituted $\mathrm{NN} 6 \mathbf{a}$ and a compound with 2-ethynylcyclopropyl substituent $\mathbf{6 c}$. The regioselectivity of $\mathrm{CH}_{2} \mathrm{~N}_{2}$ addition to triple bond is readily explained by taking into account the strongly $\pi$-electronwithdrawing and unsaturated character of the nitronyl nitroxide group.

1,3-Dipolar cycloaddition of $\mathrm{CH}_{2} \mathrm{~N}_{2}$ to activated double bond probably produces pyrazolines that easily loose a molecule of nitrogen to form a mixture of two geometric isomers of cyclopropane 6c. In certain cases we also isolated amide $\mathbf{6 b}$ as a minor product. Its possible origin is the reaction of $\mathbf{6 a}$ with methyl isocyanate, ${ }^{10}$ which is formed in the samples of $\mathrm{N}$ nitroso- $N$-methyl urea upon storage (Scheme 4). ${ }^{11}$ Regioselectivity was also observed in the interaction of 5 with $\mathrm{N}$-oxide of nitrile $\mathbf{7}$ generated in situ from ethyl chlorooximidoacetate in the presence of $\mathrm{Et}_{3} \mathrm{~N}^{12}$ that produced a disubstituted isoxazole 8 .

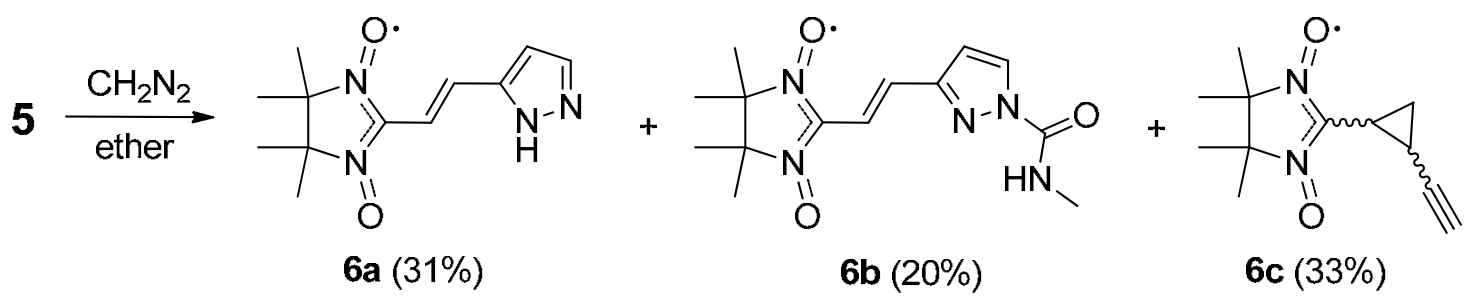




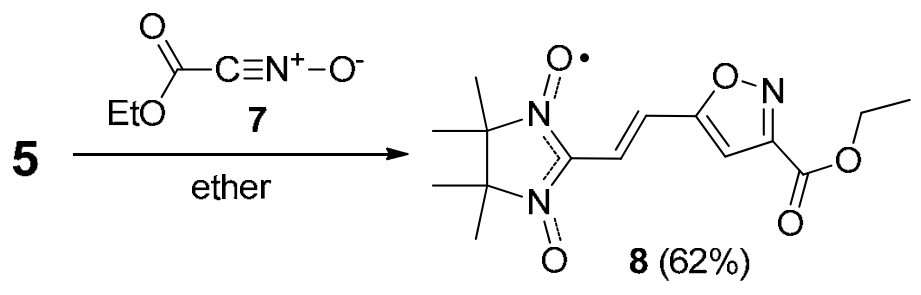

\section{Scheme 4}

Thus in the reactions of 1,3-dipolar cycloaddition enyne $\mathbf{5}$ behaves as a vinylog of ethynylsubstituted $\mathrm{NN} 9,{ }^{13}$ which upon interaction with $\mathrm{CH}_{2} \mathrm{~N}_{2}$ readily forms 3(5)-pyrazolyl-substituted $\mathrm{NN} \mathbf{1 0}$, and in the reaction with 7 produces a spin-labeled isoxazole 11 (Scheme 5).
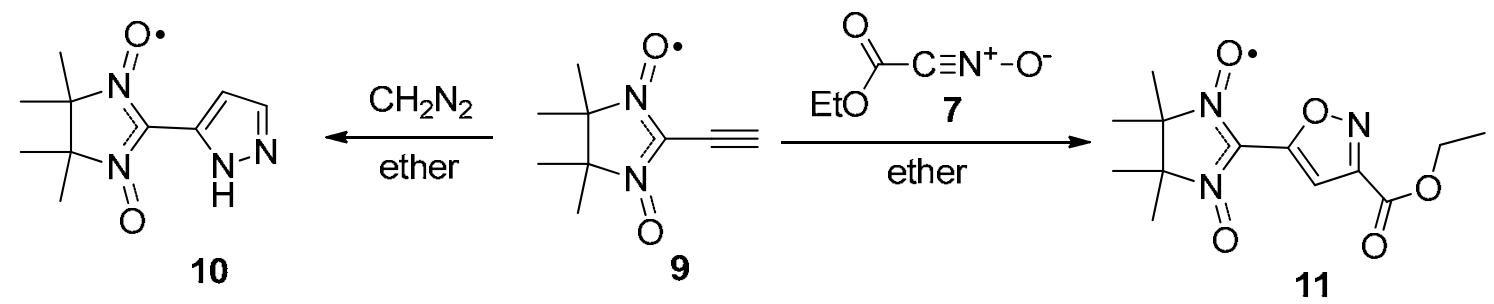

\section{Scheme 5}

At the same time nitroxides 5 and $\mathbf{9}$ behave quite differently in the reactions with secondary amines. Thus, while 9 in reaction with pyrrolidine forms exclusively the product of transaddition, ${ }^{14}$ for 5 the nucleophilic attack proceeds at the $\alpha$-carbon of the double bond to produce a mixture of optical isomers 12 (Scheme 6).

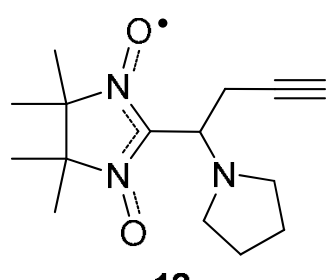

12

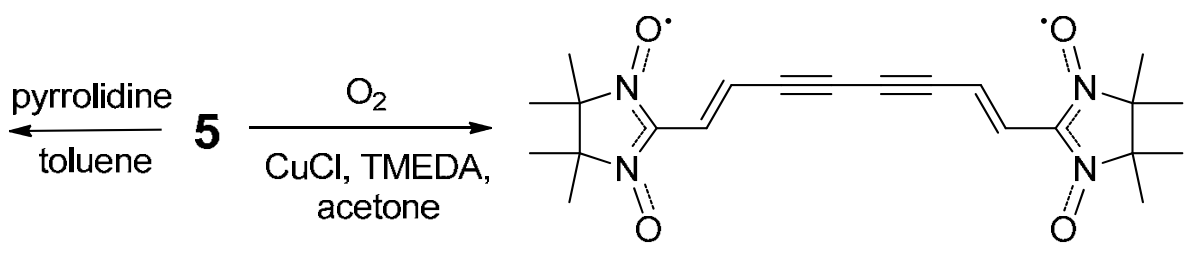

13

\section{Scheme 6}

The sensitivity of 5 to the presence of nucleophilic reagents in the reaction mixture probably precluded its oxidative coupling in classic variants $\left(\mathrm{Cu}(\mathrm{OAc})_{2}, \mathrm{Py}, 60-70{ }^{\circ} \mathrm{C}^{15}\right.$ and $\mathrm{O}_{2}, \mathrm{CuCl}$, $\mathrm{Py}^{16}$ ), as terminal alkyne 5 in these conditions rapidly decomposes. On the other hand, in the presence of a sterically hindered amine and $\mathrm{CuCl}^{17}$ the reaction proceeded smoothly to produce diradical 13 in $50 \%$ yield. 


\section{Crystal structures and magnetic properties}

Nitroxides 3a,b, 4a,b, and $\mathbf{5}$ upon crystallization from a mixture of $\mathrm{CH}_{2} \mathrm{Cl}_{2}$ with $n$-heptane formed solid phase as very thin flakes adhering to each other. For compounds $\mathbf{3 a}, \mathbf{4 a}, \mathbf{4 b}$, and $\mathbf{5}$ single crystals could be selected and analyzed by XRD. The latter demonstrated that the structure of radicals 3a, $\mathbf{4 a}$, and $\mathbf{4 b}$ is characterized by a large value of the dihedral angle $\alpha$ between the median plane of the paramagnetic fragment and the plane of the heterocycle: the angle $\alpha$ is equal to $58.9^{\circ}$ in $\mathbf{3 a}$ and $69.6^{\circ}$ in $\mathbf{4 a}$, while in two crystallographically independent radicals $\mathbf{4 b}$ the value of $\alpha$ reaches 89.7 and $86.0^{\circ}$ (Figure 1). The twist of the heterocycles is caused by the presence of vicinal phenyl substituent in $\mathbf{3 a}$ and $\mathbf{4 a}, \mathbf{b}$, with the angle between its plane and the plane of the triazine moiety being in the range $39.9-57.3^{\circ}$, and the phenyl cycle remote from the paramagnetic substituent being twisted by a smaller angle of 13.4-18.5 . Breaking of the conjugation between the paramagnetic moiety and the heterocycle imparts a non-typical for the family of NNs brown-reddish color to crystals of $\mathbf{3 a}$ and $\mathbf{3 b}$, which is preserved after dissolution of these paramagnetics, e.g., in $\mathrm{CH}_{2} \mathrm{Cl}_{2}$.
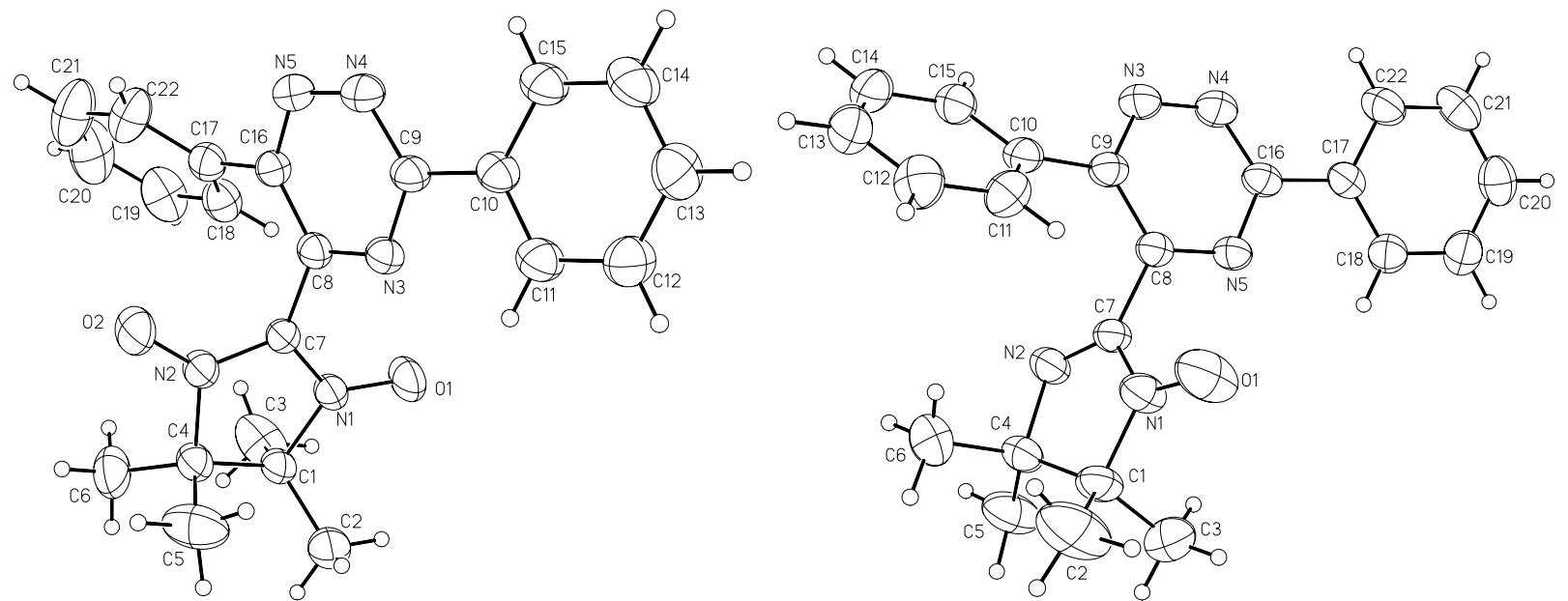

a

b

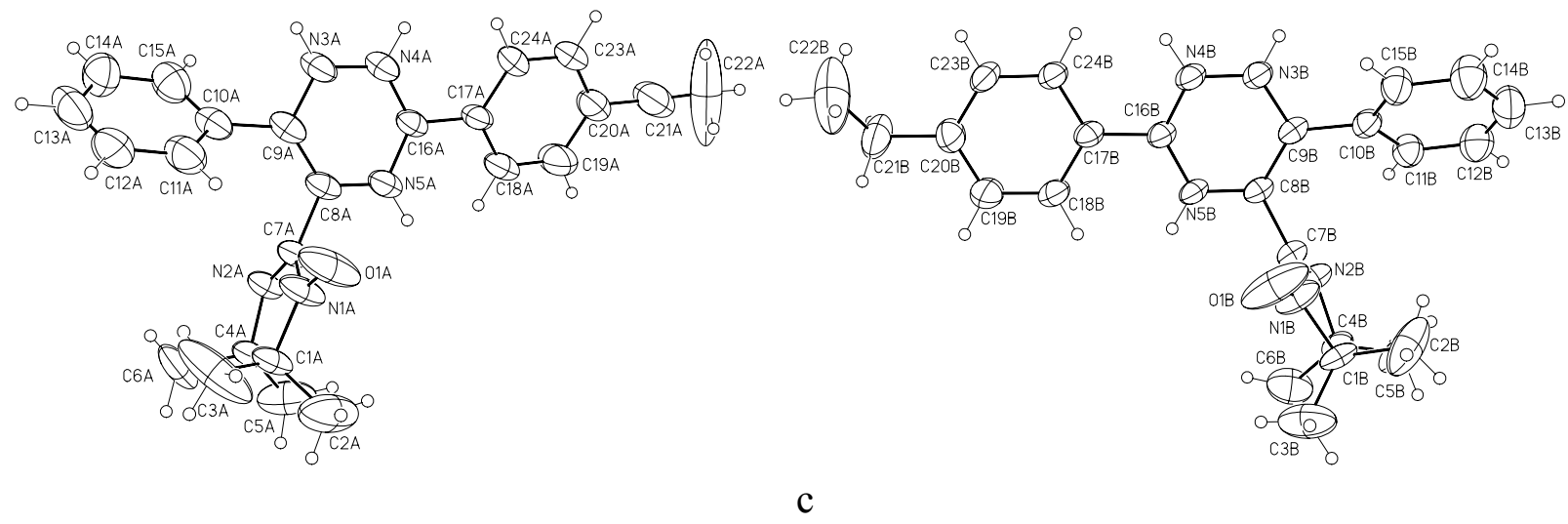

Figure 1. Structures of nitroxides $3 \mathbf{a}(\mathrm{a}), \mathbf{4 a}(\mathrm{b})$, and $\mathbf{4 b}(\mathrm{c})$. 
An important parameter for the crystal structure of nitroxides is the intermolecular distance between the paramagnetic centers, the oxygens in the N-O groups. In the structures of 3a and 4a,b these distances exceed $4.0 \AA$, which implies for them a typical behavior for a weakly coupled spin system. Indeed, the experimentally found values of effective magnetic moment ( $\mu_{\text {eff }}$ ) for $\mathbf{3 a}$ and $\mathbf{4 a , b}$ in the range 300 to $15 \mathrm{~K}$ are constant and close to $1.73 \mathrm{~B} . \mathrm{M}$. In the case of 3a the value of $\mu_{\text {eff }}$ increases up to 1.88 B.M. with decreasing the temperature down to $2 \mathrm{~K}$, indicating the domination of weak ferromagnetic interactions in solid state, for $\mathbf{4 a , b}$ the value of $\mu_{\text {eff }}$ somewhat decreases upon cooling, pointing to a weak antiferromagnetic coupling between the unpaired electrons of the paramagnetic centers, while for $\mathbf{3 b}$ it remains unchanged (see Supporting Information).

The breaking of the conjugation between the nitronyl nitroxide moiety and the $\pi$-system of the substituent mentioned above for $\mathbf{3 a}$ and $\mathbf{4 a , b}$ is not present in $\mathbf{5}$, since according to XRD data the angle $\alpha$ (the angle between the planes of $\mathrm{ONCNO}$ and $-\mathrm{CH}=\mathrm{CH}-\mathrm{C} \equiv \mathrm{CH}$ ) for it is only $5.7^{\circ}$, and the distance $\mathrm{C} 1-\mathrm{C} 8$ of $1.435(2) \AA$ is substantially shorter than single $\mathrm{C}-\mathrm{C}$ bonds (Figure 2 ). For nitroxide 5 the bond lengths $\mathrm{C} 8-\mathrm{C} 9, \mathrm{C} 10-\mathrm{C} 11$, and $\mathrm{C} 9-\mathrm{C} 10$, equal to 1.317(2), 1.163(2), and

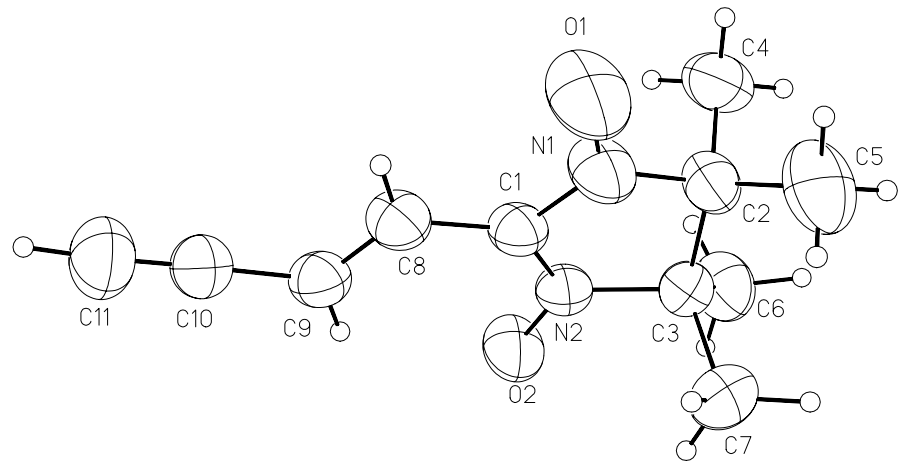

a

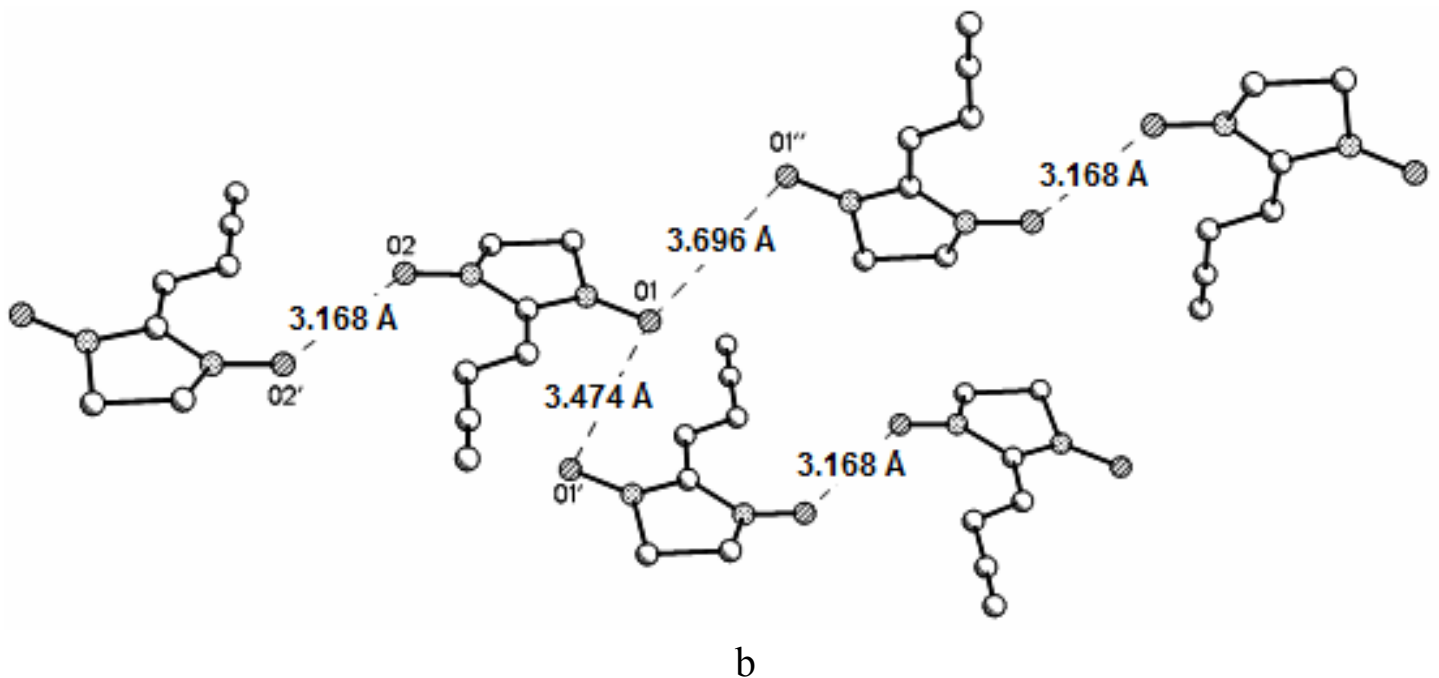

Figure 2. Structure of 5 (a) and intermolecular contacts (b) in the solid nitroxide 5. 
1.422(2) $\AA$, respectively, correspond to data for conjugate systems $\mathrm{C}=\mathrm{C}-\mathrm{C} \equiv \mathrm{C} .{ }^{18}$ The distances in the $\mathrm{N}-\mathrm{O}$ groups are practically equal, $-\mathrm{N} 2-\mathrm{O} 2$ 1.278(1) and N1-O1 1.277(1) A. Short intermolecular contacts $\mathrm{O} 2 \ldots \mathrm{O} 2$ ' (3.168 $\AA$ ) are realized in solid 5 that couple the radicals into exchange-coupled dimer. In full agreement with this the experimental dependence $\mu_{\text {eff }}(T)$ is well described within the Bleaney-Bowers mode ${ }^{19}$ for two-center $\mathrm{S}=1 / 2$ exchange clusters taking into account inter-dimer interactions in the molecular field approximation, ${ }^{20} \mathrm{~g}=2, J=-39 \mathrm{~K}$, and $\mathrm{n} J^{\prime}=-1.3 \mathrm{~K}$. (see Supporting Information).

Unequivocal determination of the structures of nitronyl nitroxides $6 \mathbf{a}$ and $\mathbf{6 b}$ required their XRD study. The necessary single crystal samples were obtained by slowly evaporating solutions of $\mathbf{6 a}$ and $\mathbf{6} \mathbf{b}$ in the mixture of $\mathrm{CH}_{2} \mathrm{Cl}_{2}$ with $n$-heptane. It was found that the structure of $\mathbf{6 a}$ is built by a packing of dimers forming via $\mathrm{N}-\mathrm{H}$... O hydrogen bonding of the radicals between the $\mathrm{NH}$ group of the pyrazolyl cycle and the oxygen of one of the NO groups (O...O distance is equal to $3.778 \AA$ ) (Figure 3). This allowed to determine the position of the $\mathrm{NH}$ fragment in the pyrazolyl

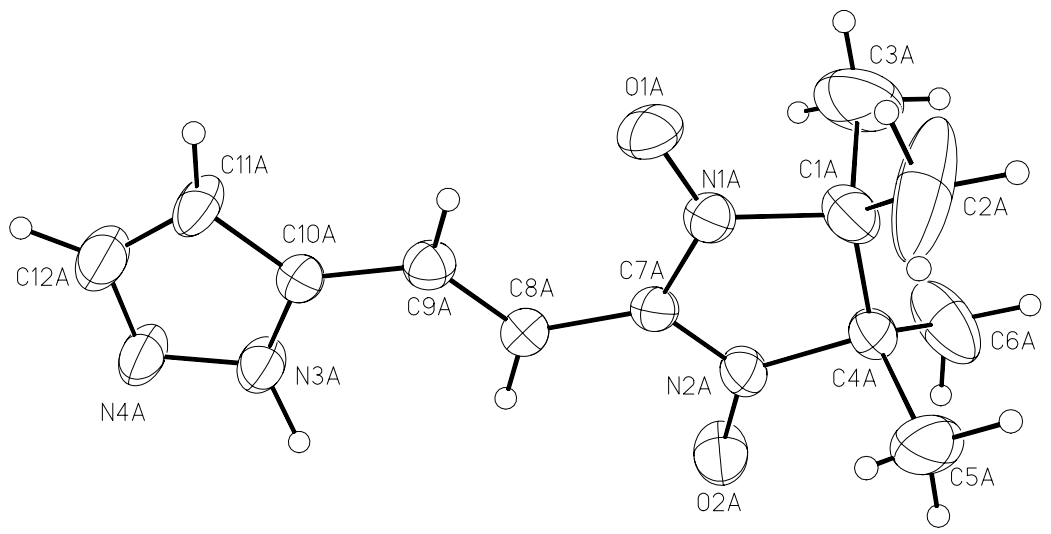

a

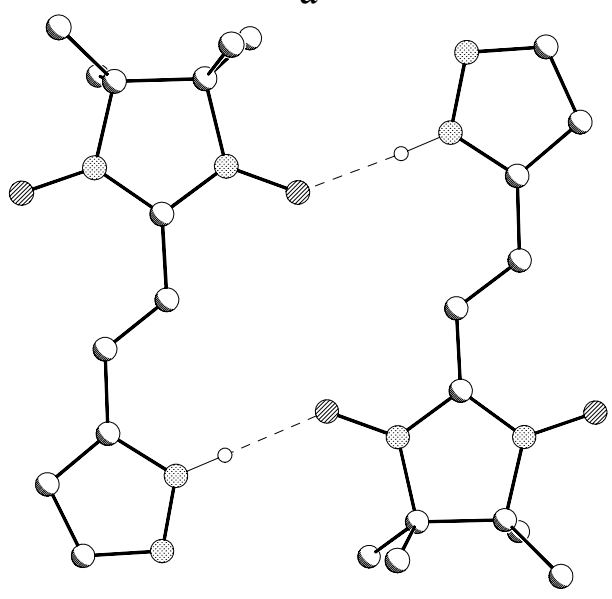

$\mathrm{b}$

Figure 3. Structure of 6a (a) and H-bonded dimer (b) in the solid nitroxide 6a. 
ring and thus to demonstrate the regiospecificity of the reaction of $\mathrm{CH}_{2} \mathrm{~N}_{2}$ addition to triple bond of the enyne 5. Although two crystallographically independent molecules of $\mathbf{6 a}$ are present in the structure of 6a, their geometric parameters are practically identical. The largest difference is found for the angle between the plane of the pyrazolyl ring and the ONCNO fragment: in one half of the nitroxides it is equal to $9.4^{\circ}$, and in another part $10.4^{\circ}$. The lengths of the $\mathrm{N}-\mathrm{O}$ bonds fall in the range $1.270(5)-1.291(5) \AA$. O...O contacts $(3.778$ and $3.781 \AA$ ) were found between dimers that lead to chains in the structure.

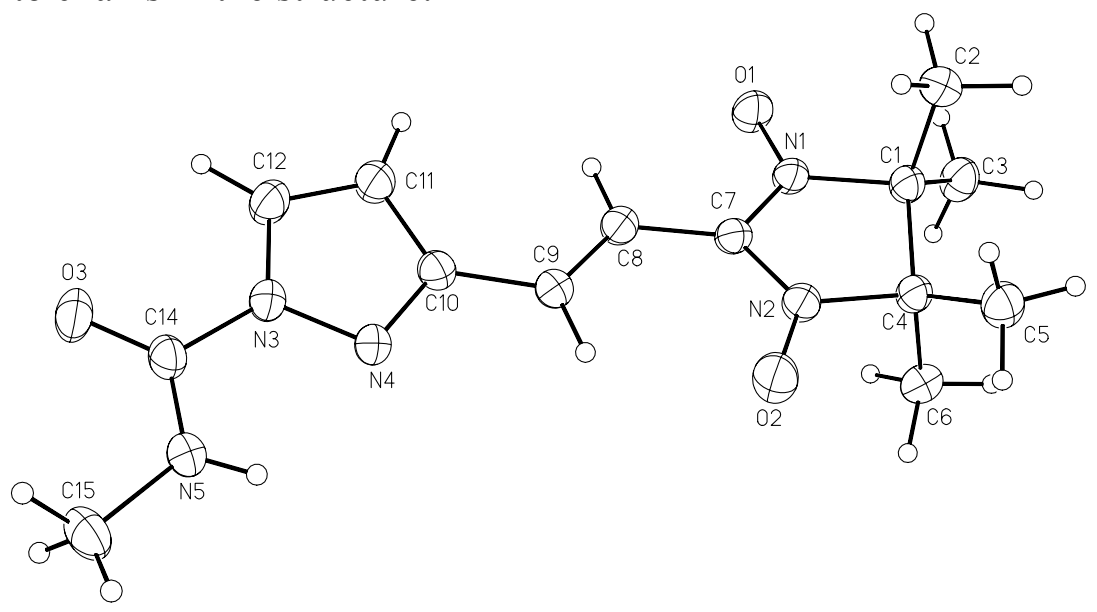

a

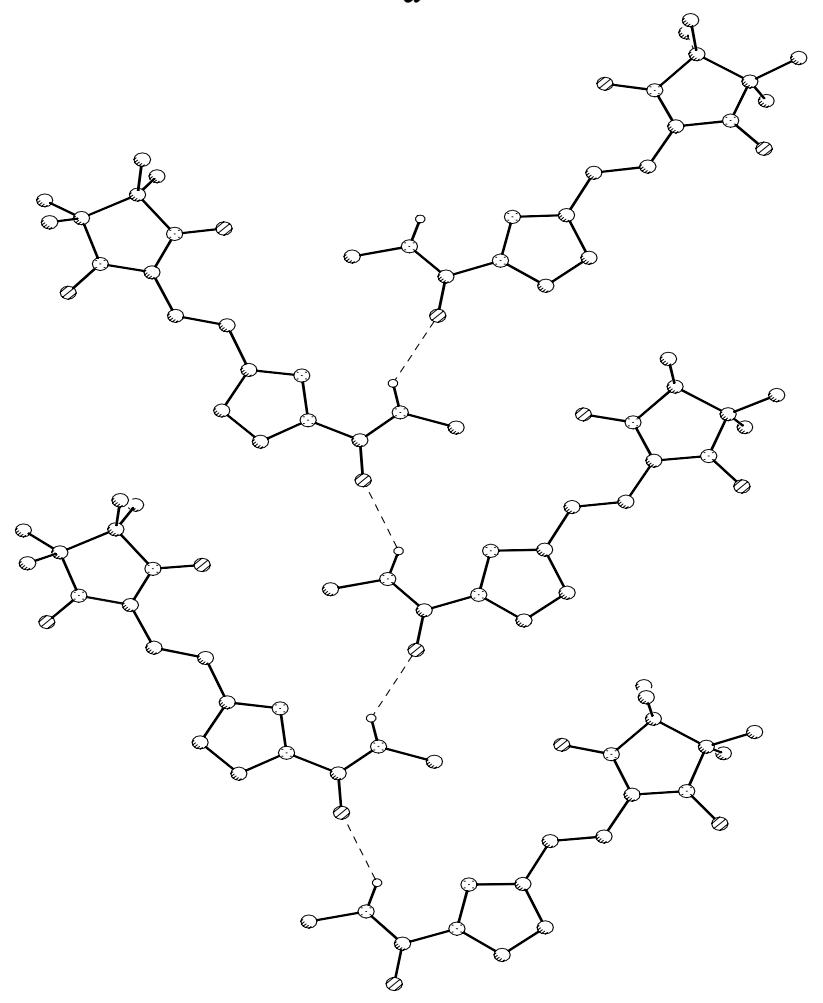

$\mathrm{b}$

Figure 4. Structure of $\mathbf{6 b}(\mathrm{a})$ and H-bonded chain (b) in the solid nitroxide $\mathbf{6 b}$. 
In radical $\mathbf{6 b}$ the value of the angle between the plane of the pyrazole cycle and the NCN fragment of the imidazoline cycle is somewhat higher than in $6 \mathbf{a}$ and is equal to $15.4^{\circ}$. The nitroxides are linked into chains due to $\mathrm{N}-\mathrm{H}$... O type hydrogen bonds between the amide groups (Figure 4). The experimentally found value of $\mu_{\mathrm{eff}}(1.73 \pm 0.01$ B.M.) for $6 \mathbf{b}$ at $75 \mathrm{~K}$ corresponds to theoretical value for a monoradical. Upon cooling of the samples below $25 \mathrm{~K}$ a decrease in the value of $\mu_{\mathrm{eff}}$ is observed indicating weak exchange interactions of antiferromagnetic character between the paramagnetic centers (see Supporting Information).

After recrystallization, nitroxide $\mathbf{6 c}$ was always isolated from mother solutions in the form of oil. It crystallized only as a trinuclear complex with copper(II) hexafluoroacetylacetonate $\left[\left(\mathrm{Cu}(\mathrm{hfac})_{2}\right)_{3}(\mathbf{6 c})_{2}\right] \cdot \mathrm{C}_{7} \mathrm{H}_{16}$, isolated as violet crystals by slowly evaporating the mixture of $n$ heptane containing equivalent amounts of $\mathrm{Cu}(\mathrm{hfac})_{2}$ and $\mathbf{6 c}$ (see Supporting Information).

Crystals of diradical 13 were grown form a mixture of ethyl acetate with $n$-heptane. According to XRD data bond lengths in $\mathrm{N}-\mathrm{O}$ groups are typical for nitroxides and fall in the range 1.26-1.30 $\AA$, the lengths of the $\mathrm{C} 10-\mathrm{C} 11$ and $\mathrm{C} 10 \mathrm{~A}-\mathrm{C} 11 \mathrm{~A}$ bonds correspond to triple bonds (1.20(2) A), and C8-C9 and C8A-C9A (1.29(2) and 1.32(2) A) bonds - to double bonds (Figure 5). In diradical 13, similar to enyne 5, single bonds C7-C8, C7A-C8A, and C11-C11A are significantly shorter than $1.54 \AA$ typical for single bonds. The angle between the planes of the NCN fragments of the imidazoline cycles in diradical 13 is equal to $48.3^{\circ}$. The diradical nature of 13 is supported by its value of the effective magnetic moment ( $\left.\mu_{\text {eff }}\right)$, which in the range 75-300 $\mathrm{K}$ is practically constant and equal to 2.45 B.M. (see Supporting Information). Since the intermolecular distances between the oxygens of the nitroxide groups are rather large (more than $4.46 \AA)$, the $\mu_{\text {eff }}(T)$ dependence displayed by 13 is determined by intramolecular antiferromagnetic exchange between the unpaired electrons. Indeed the experimental dependence $\mu_{\text {eff }}(T)$ is well described within the Bleaney-Bowers model ${ }^{19}$ for isolated two-center $\mathrm{S}=1 / 2$ exchange clusters with $\mathrm{g}=2.0$ and $J=-16 \mathrm{~K}$.

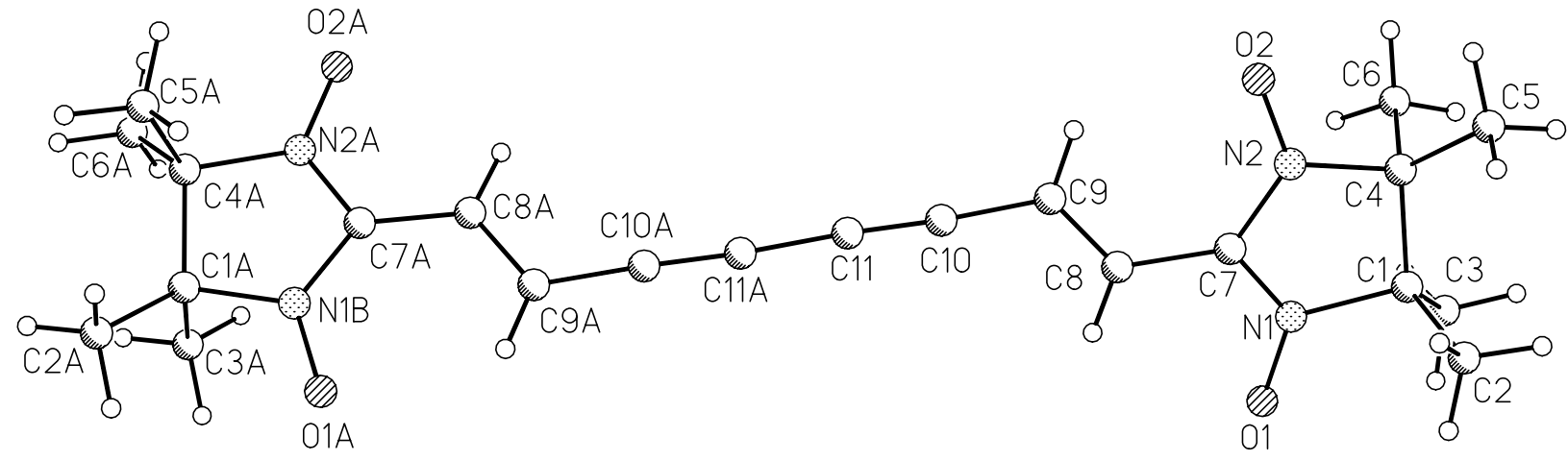

Figure 5. Structure of diradical 13.

\section{Electron paramagnetic resonance}

Figure 6a shows the experimental and simulated ESR spectra for 5. The experimental spectrum was taken in a degassed toluene solution at room temperature, concentration about $10^{-5} \mathrm{M}$, the 
estimated accuracy of determination of the hyperfine constants is $0.005 \mathrm{mT}$ (half of the modulation amplitude of $0.01 \mathrm{mT}$ ), g-value was measured using solid DPPH as the reference. Modeling of spectra yielded: $\mathrm{A}_{\mathrm{N} 1}=0.749 \mathrm{mT}, \mathrm{A}_{\mathrm{N} 2}=0.726 \mathrm{mT}, \mathrm{A}_{12 \mathrm{H}}=0.021 \mathrm{mT}, \mathrm{A}_{\mathrm{H} 1}=0.146$ $\mathrm{mT}, \mathrm{A}_{\mathrm{H} 2}=0.120 \mathrm{mT}, \mathrm{A}_{\mathrm{H} 3}=0.067 \mathrm{mT}, \mathrm{g}_{\mathrm{iso}}=2.0065$. The values of the nitrogen hyperfine couplings show that the two nuclei are not completely equivalent in solution due to a relatively rigid extended $\pi$-system encompassing the imidazoline moiety and the substituent. Furthermore, ESR spectra show rather pronounced alternating linewidth effect due to modulation of nitrogen couplings, ${ }^{21}$ most probably because of "wiggling" the substituent with respect to the imidazoline ring.
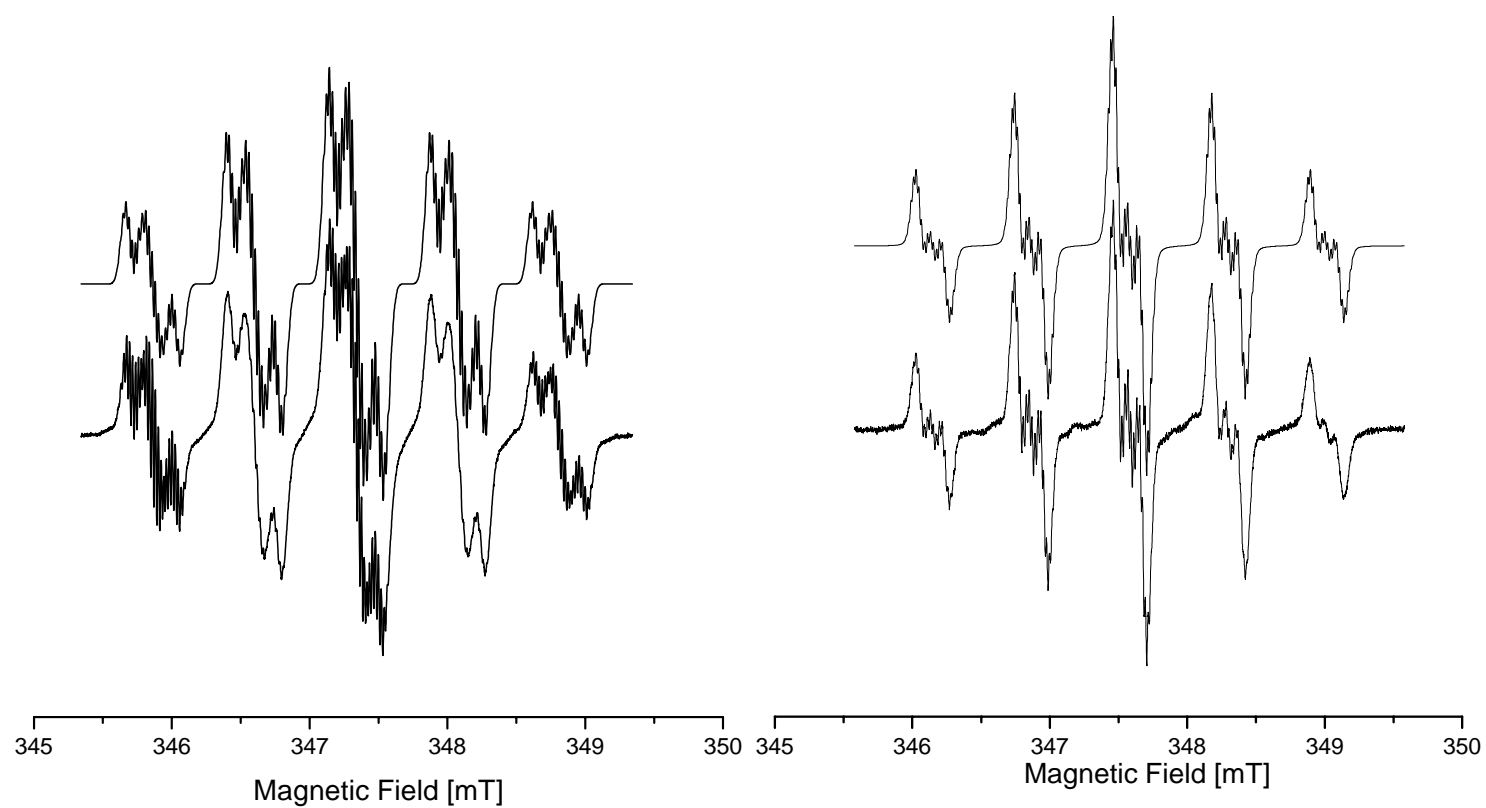

a

$\mathrm{b}$

Figure 6. ESR spectra of 5 (a) and 3a (b): experimental (bottom trace) and the result of their modeling (top trace).

Experimental and simulated ESR spectra for 3a are shown in Figure 6b. Modeling yielded: $\mathrm{A}_{2 \mathrm{~N}}=0.717 \mathrm{mT}, \mathrm{A}_{12 \mathrm{H}}=0.017 \mathrm{mT}, \mathrm{A}_{\mathrm{Na}}=0.086 \mathrm{mT}, \mathrm{A}_{\mathrm{Nb}}=0.022 \mathrm{mT}, \mathrm{A}_{\mathrm{Nc}}=0.012 \mathrm{mT}, \mathrm{g}_{\text {iso }}=2.0065$. The dominant structure of the spectrum comes from two equivalent imidazoline nitrogens, one nitrogen from the substituent, and 12 protons from the four guarding methyl groups. Two other nitrogens have rather small hyperfine coupling constants, which are not reliably determined from simulations. The spectrum for $\mathbf{3 b}$ (not shown) is almost identical, as the two radicals differ only in a remote ethyl group in the substituent that has practically no effect on the spectrum. Modeling yielded: $\mathrm{A}_{2 \mathrm{~N}}=0.716 \mathrm{mT}, \mathrm{A}_{12 \mathrm{H}}=0.018 \mathrm{mT}, \mathrm{A}_{\mathrm{Na}}=0.086 \mathrm{mT}, \mathrm{A}_{\mathrm{Nb}}=0.019 \mathrm{mT}, \mathrm{A}_{\mathrm{Nc}}=0.011$ $\mathrm{mT}, \mathrm{g}_{\text {iso }}=2.0065$.

Figure 7a shows ESR spectrum for $4 \mathbf{a}$ (bottom trace) and its modeling (top trace) that yielded the following parameters: $\mathrm{A}_{\mathrm{N} 1}=0.855 \mathrm{mT}, \mathrm{A}_{\mathrm{N} 2}=0.431 \mathrm{mT}, \mathrm{A}_{12 \mathrm{H}}=0.019 \mathrm{mT}, \mathrm{A}_{\mathrm{Na}}=0.054$ 
$\mathrm{mT}, \mathrm{A}_{\mathrm{Nb}}=0.012 \mathrm{mT}, \mathrm{A}_{\mathrm{Nc}}=0.007 \mathrm{mT}, \mathrm{g}_{\mathrm{iso}}=2.0059$. The characteristically looking spectrum is dominated by two imidazoline nitrogens with the ratio of hfc's approximately $1: 2$, with an additional nitrogen from substituent and 12 protons from the guarding methyls. Two further nitrogens with minor couplings were introduced into simulations, but these constants are too small to be reliable. As with $\mathbf{3 a} / \mathbf{b}$, the spectrum for $\mathbf{4 b}$ is very similar, as it is not sensitive to the remote ethyl. The extracted parameters are as follows: $\mathrm{A}_{\mathrm{N} 1}=0.856 \mathrm{mT}, \mathrm{A}_{\mathrm{N} 2}=0.431 \mathrm{mT}$, $\mathrm{A}_{12 \mathrm{H}}=0.019 \mathrm{mT}, \mathrm{A}_{\mathrm{Na}}=0.054 \mathrm{mT}, \mathrm{A}_{\mathrm{Nb}}=0.012 \mathrm{mT}, \mathrm{A}_{\mathrm{Nc}}=0.008 \mathrm{mT}, \mathrm{g}_{\text {iso }}=2.0060$, with two smaller couplings being not very reliable.

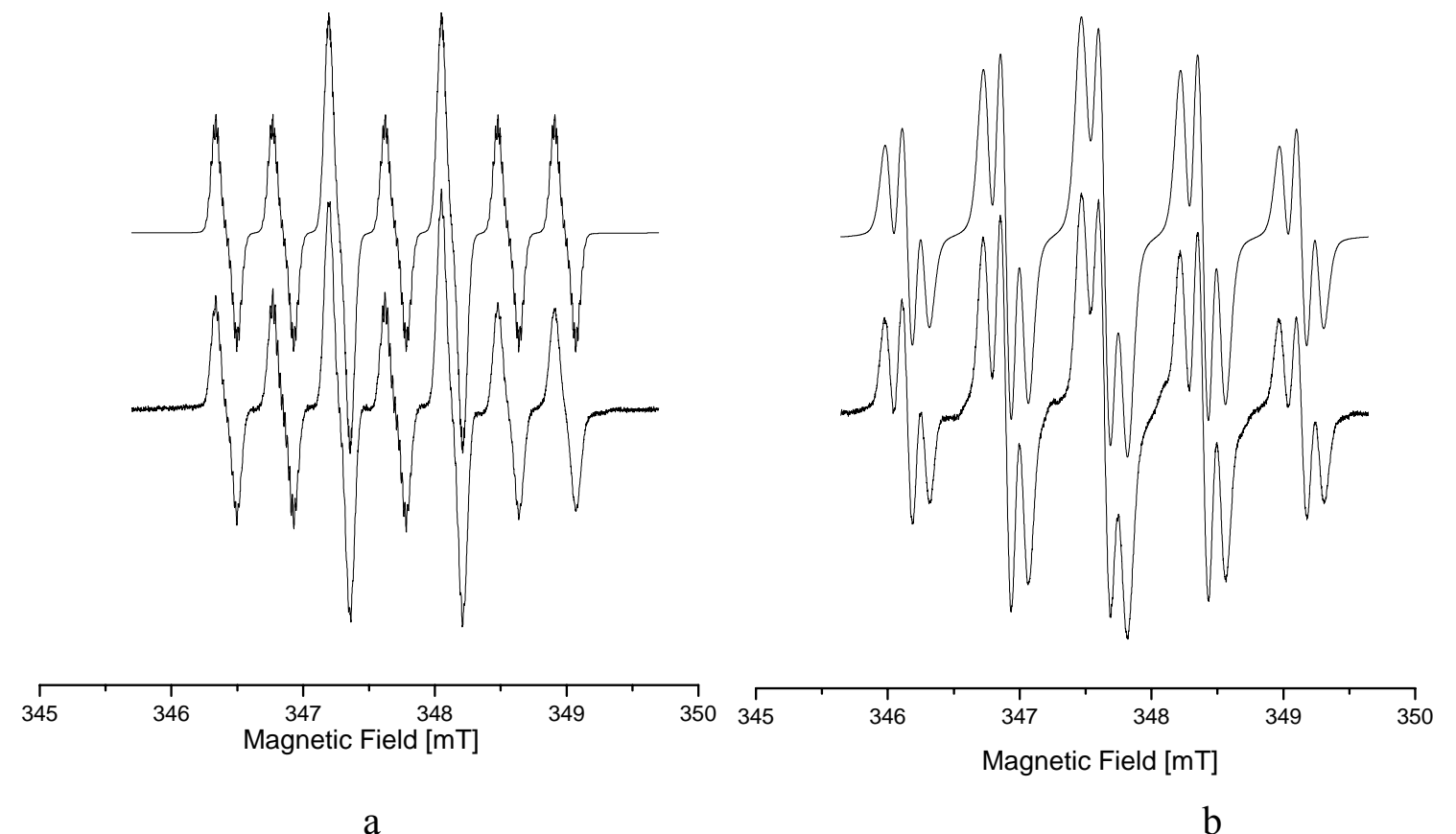

Figure 7. ESR spectra of 4a (a) and 6a (b): experimental (bottom trace) and the result of their modeling (top trace).

Figure $7 \mathrm{~b}$ shows the spectra for 6a. The dominant structure comes from two slightly nonequivalent imidazoline nitrogens, due to locked structure of the radical in solution with hindered relative motion of the imidazoline and the substituent, and two bridge protons. The spectrum is not resolved, but the standard substructure of 12 protons from the four guarding methyl groups reproduces the widths of the lines. Further nuclei with small hfc's could have been introduced in modeling, but the spectrum does not warrant this as it lacks finer details that need to be reproduced in simulations. The parameters are: $\mathrm{A}_{\mathrm{N} 1}=0.732 \mathrm{mT}, \mathrm{A}_{\mathrm{N} 2}=0.762 \mathrm{mT}, \mathrm{A}_{12 \mathrm{H}}=0.016 \mathrm{mT}$, $\mathrm{A}_{\mathrm{Ha}}=0.137 \mathrm{mT}, \mathrm{A}_{\mathrm{Hb}}=0.114 \mathrm{mT}, \mathrm{g}_{\text {iso }}=2.0066$.

Figure 8a shows ESR spectra for 8. Modeling (the top spectrum) yielded: $A_{N 1}=0.735 \mathrm{mT}$, $\mathrm{A}_{\mathrm{N} 2}=0.725 \mathrm{mT}, \mathrm{A}_{12 \mathrm{H}}=0.019 \mathrm{mT}, \mathrm{A}_{\mathrm{Ha}}=0.122 \mathrm{mT}, \mathrm{A}_{\mathrm{Hb}}=0.139 \mathrm{mT}, \mathrm{A}_{\mathrm{Hc}}=0.026 \mathrm{mT}, \mathrm{A}_{\mathrm{Na}}=0.036 \mathrm{mT}$, $\mathrm{g}_{\text {iso }}=2.0066$. The dominant structure comes from two nearly equivalent imidazoline nitrogens 
(this produces the alternating resolved/unresolved substructures of the lines in the quintet), two bridge protons, and 12 methyl protons.

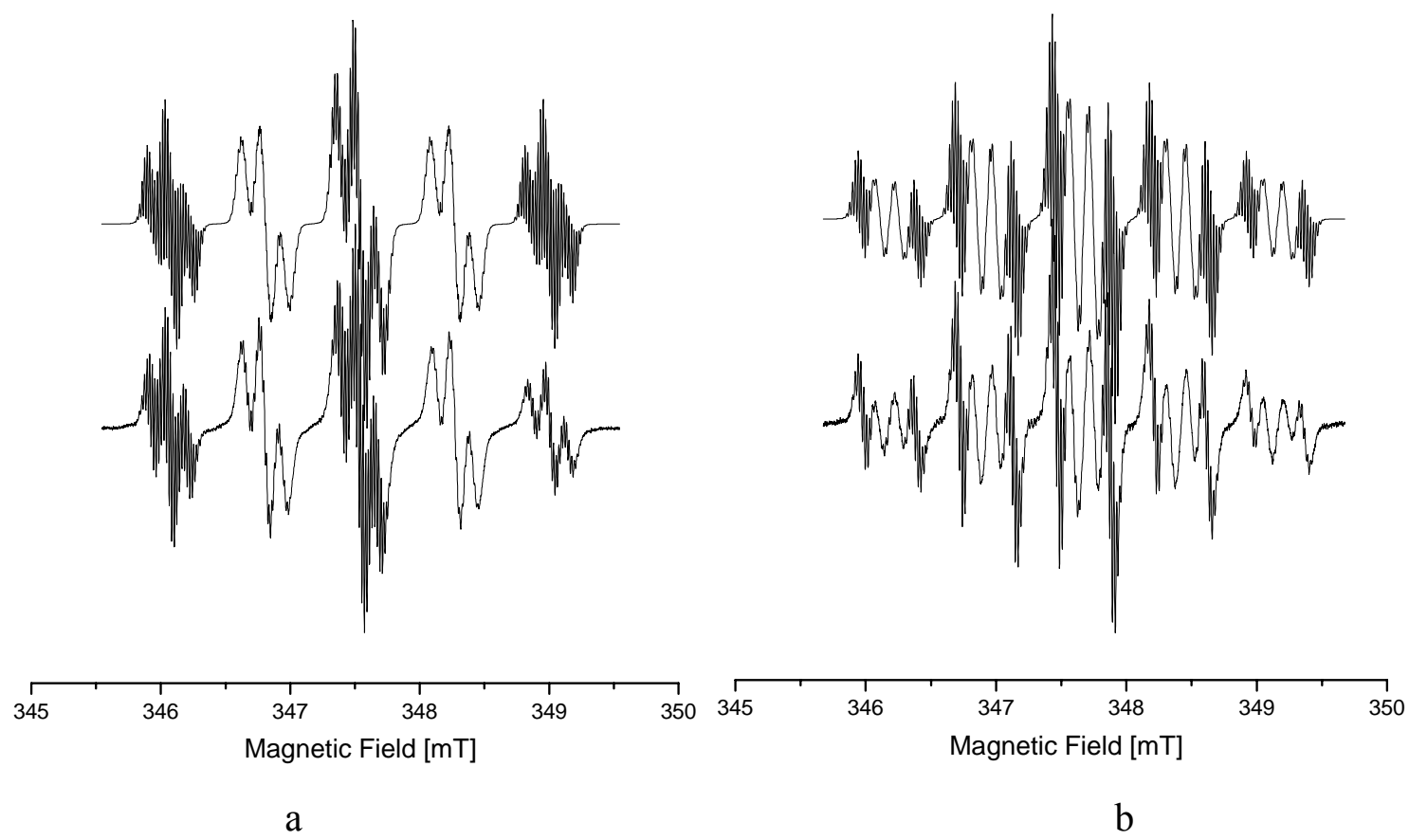

Figure 8. ESR spectra of 8 (a) and 12 (b): experimental (bottom trace) and the result of their modeling (top trace).

Figure $8 \mathrm{~b}$ shows the rather weird looking spectrum for $\mathbf{1 2}$ that was well reproduced in modeling (top trace). The spectrum has a peculiar substructure of the lines of the 12321 quintet from two imidazoline nitrogens - a quartet of lines with two outermost lines showing a resolved substructure, while the two inner lines are unresolved. The dominant structure comes from two equivalent imidazoline nitrogen (the modeling invariably produced equal values for two independently varied couplings), one proton and one nitrogen with rather large couplings, a standard set of 12 methyl protons, and two slightly different protons, most likely methylene ones (it is their "difference" that produces the specific look of the spectrum). The obtained parameters are: $\mathrm{A}_{2 \mathrm{~N}}=0.744 \mathrm{mT}, \mathrm{A}_{12 \mathrm{H}}=0.022 \mathrm{mT}, \mathrm{A}_{\mathrm{Ha}}=0.115 \mathrm{mT}, \mathrm{A}_{\mathrm{Na}}=0.146 \mathrm{mT}, \mathrm{A}_{\mathrm{Hb}}=0.037 \mathrm{mT}, \mathrm{A}_{\mathrm{Hc}}=0.026$ $\mathrm{mT}, \mathrm{g}_{\text {iso }}=2.0066$.

Spectra for $\mathbf{6 c}$ in Figure 9a show the dominating structure from two equivalent imidazoline nitrogens and 12 methyl protons, but reproduction of the width of the lines (having a resolved substructure) required introduction of further nuclei with small hfc's consistent with the chemical structure of the radical (three independent protons and two equivalent protons in the cyclopropane ring). The modeling reproducibly gives equivalent coupling for the two imidazoline nitrogens, and yielded the following parameters: $\mathrm{A}_{2 \mathrm{~N}}=0.747 \mathrm{mT}, \mathrm{A}_{12 \mathrm{H}}=0.021 \mathrm{mT}$, $\mathrm{A}_{\mathrm{Ha}}=0.044 \mathrm{mT}, \mathrm{A}_{\mathrm{Hb}}=0.028 \mathrm{mT}, \mathrm{A}_{\mathrm{Hc}}=0.023 \mathrm{mT}, \mathrm{A}_{2 \mathrm{H}}=0.046 \mathrm{mT}, \mathrm{g}_{\text {iso }}=2.0064$. 


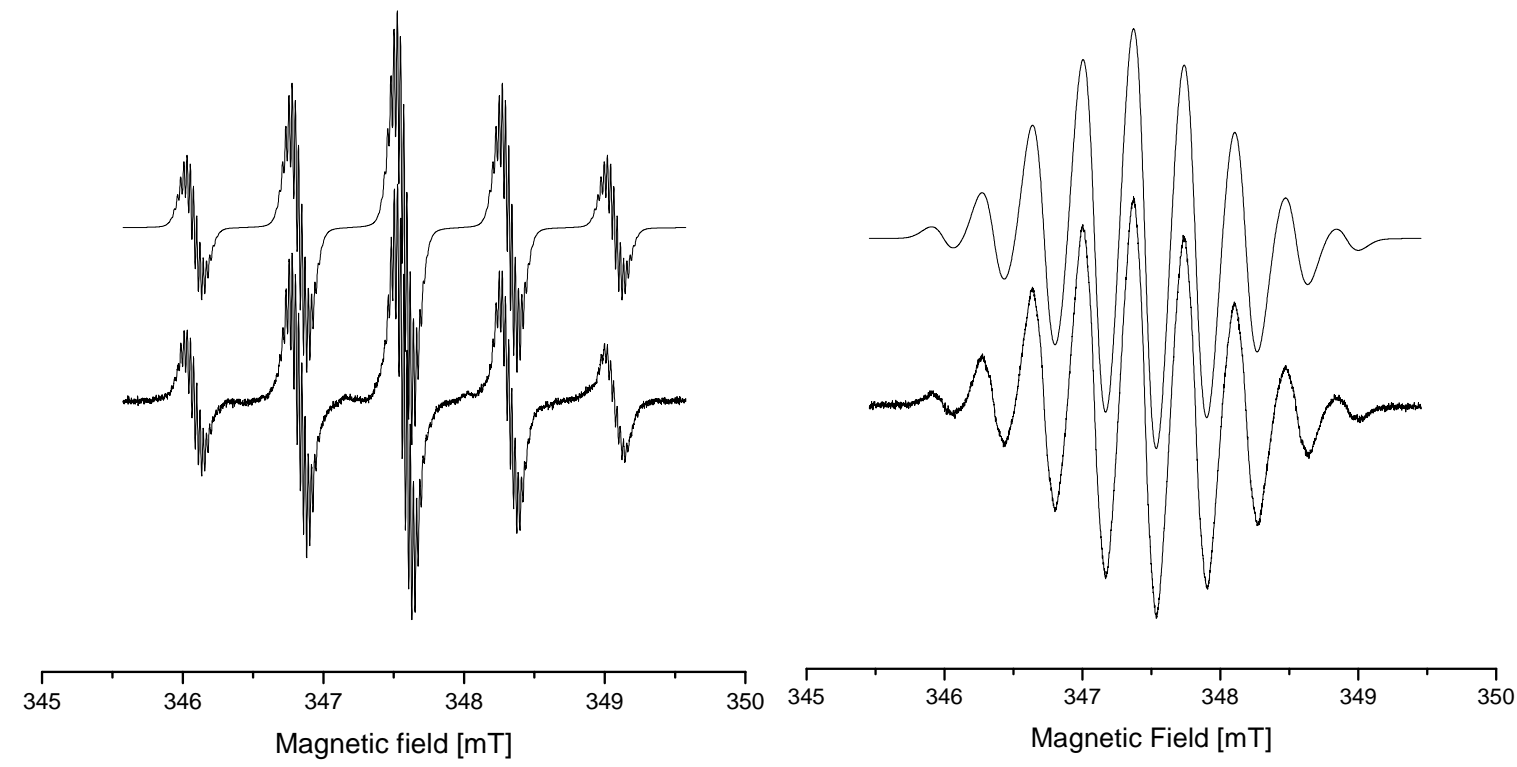

a

b

Figure 9. ESR spectra of 6c (a) and 13 (b): experimental (bottom trace) and the result of their modeling (top trace).

Finally, the Figure 9b shows the spectra for diradical $\mathbf{1 3}$ and its modeling that faithfully reproduces the experiment. The spectrum corresponds to fast exchange limit with couplings to four equivalent nitrogens of two imidazoline moieties $\mathrm{A}_{4 \mathrm{~N}}=0.365 \mathrm{mT}$ and the peak-to-peak width of unresolved lines $\Delta \mathrm{H}_{\mathrm{pp}}=0.091 \mathrm{mT}, \mathrm{g}_{\mathrm{iso}}=2.0064$. The diradical is rather stable in degassed toluene solution, and after about ten hours, when the temperature of solution was varied from $183 \mathrm{~K}$ to $353 \mathrm{~K}$ (approximately melting and boiling points of toluene) and the sample was then cooled down back to room temperature, gave the same spectrum as the freshly prepared sample, both in terms of shape and intensity. No signs of monoradical spectra were traced, and there were no changes to the spectrum itself during the extended temperature experiment apart from the expected transformation from non-isotropic to isotropic spectrum upon melting of the matrix, and additional line broadening due to accelerated spin exchange at elevated temperatures. The diradical is thus kinetically and magnetically stable in degassed toluene solution.

\section{Conclusions}

In this work convergent schemes of nitroxide synthesis based on $\mathrm{S}_{\mathrm{N}}{ }^{\mathrm{H}}$ reactions of 4,4,5,5tetramethyl-4,5-dihydro-1 $H$-imidazol-3-oxide-1-oxyl lithium salt with activated azines, 3,6diaryl-1,2,4-triazines and pyridazine- $N$-oxide are suggested. Using these schemes a broad range of new polyfunctional nitronyl and imino nitroxides was obtained, viz.: 1,2,4-triazinyl-, buten-3ynyl-, 2-(1H-pyrazol-5-yl)vinyl-, $\quad$ 2-ethynylcyclopropyl-, 2-(3-(ethoxycarbonyl)isoxazol-5- 
yl)vinyl-, 1-(pyrrolidin-1-yl)but-3-ynyl-substituted nitronyl nitroxides, as well as a diradical, 2,2'-((1E,7E)-octa-1,7-dien-3,5-diyne-1,8-diyl)bis(4,4,5,5-tetramethyl-4,5-dihydro-1H-imidazol3-oxide-1-oxyl). The results of this work expand the views of the synthetic potential of $\mathrm{S}_{\mathrm{N}}{ }^{\mathrm{H}}$ reactions and may prove useful for the development of synthetic strategies towards new magnetoactive systems.

\section{Experimental Section}

General. Pyridazine-1-oxide, ${ }^{22}$ 2,3-bis(hydroxyamino)-2,3-dimethylbutane sulphate monohydrate ${ }^{23}$ and ethyl 2-chloro-2-(hydroxyimino)acetate ${ }^{24} \mathbf{8}$ were synthesized as described in literature. THF was distilled from sodium benzophenone ketyl in a recycling still. Other reagents and solvents from commercial sources were of the highest purity available and were used as received. The reactions were monitored by TLC using "Silica gel $60 \mathrm{~F}_{254}$ aluminum sheets, Merck". Chromatography was carried out with the use of "Merck" silica gel $(0.063-0.100 \mathrm{~mm}$ for column chromatography) for column chromatography. $\mathrm{C}, \mathrm{H}$, and $\mathrm{N}$ elemental analyses were carried out by the Chemical Analytical Center of the Novosibirsk Institute of Organic Chemistry. The melting points were determined on a Boethius apparatus and were not corrected. Infrared spectra (4000-400 $\mathrm{cm}^{-1}$ ) were recorded with a Bruker VECTOR 22 instrument in $\mathrm{KBr}$ pellets. UV/Vis spectrum of diradical 13 was registered with Hewlett Packard 8453 spectrophotometer. $\mathrm{X}$-Band CW ESR spectra were recorded in dilute degassed toluene solutions at room temperature on a Bruker EMX spectrometer and modeled in free package Winsim v.0.96 as described earlier. $^{25}$ The magnetochemical experiment was run on an MPMS-5S ("Quantum Design") SQUID magnetometer at temperatures from $2 \mathrm{~K}$ to $300 \mathrm{~K}$ in a homogeneous external magnetic field of up to $49.5 \mathrm{kOe}$. The molar magnetic susceptibility $\chi$ was calculated using Pascal's additive scheme including diamagnetic corrections.

4,4,5,5-Tetramethyl-4,5-dihydro-1H-imidazol-3-oxide-1-oxyl $\quad(H 1) .^{3}$ Stage 1. To the suspension of 2,3-bis(hydroxyamino)-2,3-dimethylbutane sulphate monohydrate (25 g, 0.095 $\mathrm{mol})$ in $80 \mathrm{ml}$ of water $37 \%$ aqueous solution of $\mathrm{CH}_{2} \mathrm{O}(8.1 \mathrm{~g}, 0.1 \mathrm{~mol})$ was added dropwise over the period of 30 minutes (the reaction is conveniently performed in a high $200 \mathrm{ml}$ flask). The solution was quenched with $\mathrm{NaHCO}_{3}$ (using 1-5 ml of benzene to inhibit foaming) until no more $\mathrm{CO}_{2}$ was evolving. The white product was filtered off, washed with water, washed with acetone, air-dried, and recrystallized from $\mathrm{MeOH}$ with filtration (about $250 \mathrm{ml}$ of $\mathrm{MeOH}$ was needed to recrystallize $2 \mathrm{~g}$ ). Yield of 4,4,5,5-tetramethylimidazoline-1,3-diol is $6.95 \mathrm{~g}$ (46\%), mp. 153-165 ${ }^{\circ} \mathrm{C}$ (accompanied by evolution of gas bubbles). IR: $v=494,515,548,594,753,795,908,954$, 1016, 1060, 1093, 1120, 1145, 1163, 1279, 1331, 1368, 1389, 1454, 2883, 2986, 3220 broad $\mathrm{cm}^{-1} .{ }^{1} \mathrm{H}$ NMR (400 MHz, DMSO-d $): \delta 0.96(\mathrm{~s}, 12 \mathrm{H}, \mathrm{Me}) ; 3.87$ (s, $\left.2 \mathrm{H}, \mathrm{CH}_{2}\right) ; 7.64$ (s, $2 \mathrm{H}$, $\mathrm{OH}) .{ }^{13} \mathrm{C}$ NMR $\left(100 \mathrm{MHz}, \mathrm{DMSO}-d_{6}\right): \delta 79.8\left(\mathrm{C}^{2}\right), 67.1\left(\mathrm{C}^{4,5}\right), 20.2 \operatorname{broad}\left(\mathrm{CH}_{3}\right)$. 
Stage 2. To a cooled at about $5{ }^{\circ} \mathrm{C}$ mixture of 4,4,5,5-tetramethylimidazoline-1,3-diol (16 g, 0.1 $\mathrm{mol}), \mathrm{CHCl}_{3}(150 \mathrm{ml})$ and water $(150 \mathrm{ml}) \mathrm{NaIO}_{4}(34.2 \mathrm{~g}, 0.16 \mathrm{~mol})$ was added in small portions under stirring over the period of $40 \mathrm{~min}$. After further stirring for $30 \mathrm{~min}$ the organic layer was separated. The aqueous layer was filtered (from $\left.\mathrm{NaIO}_{3}\right)$ and extracted with $\mathrm{CHCl}_{3}(3 \times 30 \mathrm{ml})$. The organic phases were combined, dried over $\mathrm{Na}_{2} \mathrm{SO}_{4}$ and filtered through a layer of $\mathrm{Al}_{2} \mathrm{O}_{3}$ $(2 \times 15 \mathrm{~cm})$. The solution was diluted with $30 \mathrm{ml}$ of $n$-heptane and evaporated (pressure $70 \mathrm{~mm}$ $\mathrm{Hg}$, bath at room temperature) until the onset of product crystallization, after which the flask was kept at about $-10{ }^{\circ} \mathrm{C}$ for $20 \mathrm{~h}$. The residue was filtered off and washed on filter with cold $n$ hexane to give $13.8 \mathrm{~g}(88 \%)$ of $0.5-3 \mathrm{~mm}$ dark-red crystals covered with small yellowish crystals visible in a microscope. The product, which according to TLC and IR data contained a minute amount of 1,3-dihydroxy-4,4,5,5-tetramethylimidazolidyn-2-one and 2-iodo-4,4,5,5-tetramethyl4,5-dihydro- $1 H$-imidazol-3-oxide-1-oxyl, was used in synthesis without additional purification, because in the course of the differentiating procedures the content of admixtures further increased. To prepare a reference sample nitroxide $\mathbf{H 1}$ was crystallized from $n$-hexane, and darkred flakes were manually selected from the deposited crystals, mp. $125-127{ }^{\circ} \mathrm{C}$. IR: $v=3075$, 2988, 1454, 1403, 1372, 1323, 1268, 1199, 1136, 956, 819, 775, 692, 613, 564, 531, $431 \mathrm{~cm}^{-1}$.

3,6-Diphenyl-1,2,4-triazine (2a) was prepared from 3,6-diphenyl-1,2,4-triazine-4-oxide according to literature, ${ }^{26}$ yield $75 \%$, yellow needles, mp $157-160{ }^{\circ} \mathrm{C}$ with decomposition (lit. ${ }^{27}$ $\left.160{ }^{\circ} \mathrm{C}\right)$.

3-(4-Ethylphenyl)-6-phenyl-1,2,4-triazine (2b) was prepared from 3-(4-ethylphenyl)-6diphenyl-1,2,4-triazine-4-oxide; yield $85 \%$, yellow powder, mp. $140{ }^{\circ} \mathrm{C}, R_{\mathrm{f}} 0.30\left(\mathrm{C}_{6} \mathrm{H}_{6}\right) . \mathrm{IR}: v=$ $=581,686,764,801,849,1017,1029,1085,1178,1312,1399,1416,1442,1505,1556,1582$, 1606, 2864, 2925, 2959, 3030, $3054 \mathrm{~cm}^{-1} .{ }^{1} \mathrm{H}$ NMR (400 MHz, DMSO-d $\left./ \mathrm{CCl}_{4}\right): \delta 1.31(\mathrm{t}, 3 \mathrm{H}$, $\left.J=7.52 \mathrm{~Hz}, \mathrm{CH}_{3}\right) ; 2.75$ (q, $\left.2 \mathrm{H}, J=7.52 \mathrm{~Hz}, \mathrm{CH}_{2}\right) ; 7.38$ (m, $\left.2 \mathrm{H}, \mathrm{Ph}\right) ; 7.39-7.60$ (m, $\left.3 \mathrm{H}, \mathrm{Ph}\right)$; $8.23\left(\mathrm{~m}, 2 \mathrm{H}, \mathrm{C}_{6} \mathrm{H}_{4}\right) ; 8.42\left(\mathrm{~m}, 2 \mathrm{H}, \mathrm{C}_{6} \mathrm{H}_{4}\right) ; 9.33$ (s, $\left.1 \mathrm{H}\right)$. Anal. Calcd. for $\mathrm{C}_{17} \mathrm{H}_{15} \mathrm{~N}_{3}$ (262.33): C, 78.13; H, 5.79; N, 16.08. Found: C, 78.26; H, 5.67; N, 16.23.

(E)-2-(But-1-en-3-ynyl)-1-hydroxy-4,4,5,5-tetramethyl-4,5-dihydro-1H-imidazol-3-oxide-1oxyl (5). To a vigorously stirred solution of H1 (157 mg, $1.0 \mathrm{mmol})$ in $3 \mathrm{ml}$ of absolute THF a $2.0 \mathrm{M}$ solution of LDA (or $1.06 \mathrm{M}$ of $\left.\mathrm{LiN}\left(\mathrm{SiMe}_{3}\right)_{2}\right)$ in THF $\left(1.1 \mathrm{mmol}\right.$ ) was added at $-78{ }^{\circ} \mathrm{C}$ under argon atmosphere. The reaction mixture was stirred at $-78{ }^{\circ} \mathrm{C}$ for $20 \mathrm{~min}$. To the obtained bright-red solution of the lithiated derivative Li1 a solution of pyridazine- $N$-oxide (106 mg, 1.1 $\mathrm{mmol}$ ) in $4 \mathrm{ml}$ of THF was added at $-78{ }^{\circ} \mathrm{C}$ under argon atmosphere, and the reaction mixture turned into a greenish-brown suspension. The cooling bath was removed; the reaction mixture was stirred for $2 \mathrm{~h}$ and concentrated in vacuo. The obtained residue was put through a column with $\mathrm{SiO}_{2}$ using ethylacetate as the eluent. The blue-colored fraction was evaporated until dry under reduced pressure, the obtained residue was recrystallized from a mixture of $n$-heptane and $\mathrm{CH}_{2} \mathrm{Cl}_{2}$. Yield $141 \mathrm{mg}(68 \%)$, blue-green crystals, mp. $94-98{ }^{\circ} \mathrm{C}$ (with decomposition), $R_{\mathrm{f}} 0.65$ (EtOAc). IR: $v=3259,3067,3042,2993,2925,2853,2613,2094,1824,1593,1479,1449$, $1425,1386,1370,1284,1263,1217,1165,1136,1022,979,861,679,637,616,541,483,475$, 
$424 \mathrm{~cm}^{-1}$. $\mu_{\text {eff }} \sim 1.73 \mu_{\mathrm{B}}(200-300 \mathrm{~K})$. Anal. Calcd. for $\mathrm{C}_{11} \mathrm{H}_{15} \mathrm{~N}_{2} \mathrm{O}_{2}$ (207.25): C, 63.75; H, 7.30; N, 13.52. Found: C, 63.80; H, 7.55; N, 13.14.

\section{4,4,5,5-Tetramethyl-2-(3,6-diphenyl-1,2,4-triazin-5-yl)-4,5-dihydro-1H-imidazol-3-oxide-1-} oxyl (3a) and 4,4,5,5-tetramethyl-2-(3,6-diphenyl-1,2,4-triazin-5-yl)-4,5-dihydro-1Himidazol-1-oxyl (4a). To a stirred solution of H1 (157 mg, $1.0 \mathrm{mmol})$ in $3 \mathrm{ml}$ THF a $2.0 \mathrm{M}$ solution of LDA (or $1.06 \mathrm{M}$ of $\left.\mathrm{LiN}\left(\mathrm{SiMe}_{3}\right)_{2}\right)$ in THF $(1.1 \mathrm{mmol})$ was added at $-78{ }^{\circ} \mathrm{C}$ under argon atmosphere. The reaction mixture was stirred at $-78{ }^{\circ} \mathrm{C}$ for $20 \mathrm{~min}$. To the obtained brightred solution of Li1 a solution of 3,6-diphenyl-1,2,4-triazine 2a (256 mg, $1.1 \mathrm{mmol})$ in $6 \mathrm{ml} \mathrm{THF}$ was added at $-78{ }^{\circ} \mathrm{C}$ under argon atmosphere. The obtained burgundy-colored suspension was stirred for $2 \mathrm{~h}$ at room temperature and concentrated in vacuo. The residue was purified on a column with $\mathrm{SiO}_{2}$ using a mixture of benzene and ethyl acetate $(9: 1)$ as the eluent. The fractions containing 3a and $\mathbf{4 a}$ were concentrated at reduced pressure, the residues were recrystallized from a mixture of $n$-heptane with $\mathrm{CH}_{2} \mathrm{Cl}_{2}$, the produced crystals were dried in vacuum.

Compound (3a). Yield $123 \mathrm{mg}(32 \%)$, brown-red crystals, mp $180-181{ }^{\circ} \mathrm{C}, R_{\mathrm{f}} 0.15\left(\mathrm{C}_{6} \mathrm{H}_{6}-\right.$ ethyl acetate, 9:1). IR: $v=3061,2991,2976,2926,2868,1601,1524,1500,1453,1417,1395$, $1369,1261,1219,1182,1136,1072,1055,1024,918,873,775,699,556,473 \mathrm{~cm}^{-1}$. HRMS, $m / z$ : $388.1774\left(\mathrm{M}^{+}\right.$, calcd. for $\mathrm{C}_{22} \mathrm{H}_{22} \mathrm{~N}_{5} \mathrm{O}_{2}$ 388.1768). MS, $m / z(\%): 388\left(\mathrm{M}^{+}, 100\right), 288(11), 259$ (13), 257 (41), 169 (10), 129 (10), 128 (13), 127 (27), 105 (34), 103 (15), 84 (43), 69 (27). $\mu_{\mathrm{eff}} \sim$ $1.73 \mu_{\mathrm{B}}(50-300 \mathrm{~K})$. Anal. Calcd. for $\mathrm{C}_{22} \mathrm{H}_{22} \mathrm{~N}_{5} \mathrm{O}_{2}$ (388.45): C, 68.0; H, 5.7; N, 18.0. Found: C, $68.1 ; \mathrm{H}, 5.9 ; \mathrm{N}, 18.0$.

Compound (4a). Yield $130 \mathrm{mg}$ (35\%), bright-orange crystals, mp. $163-165{ }^{\circ} \mathrm{C}, R_{\mathrm{f}} 0.40\left(\mathrm{C}_{6} \mathrm{H}_{6}-\right.$ ethyl acetate, 9:1). IR: $v=3061,2991,2976,2926,1500,1453,1395,1369,1261,1159,1072$, 1024, 803, 769, 699, $556 \mathrm{~cm}^{-1}$. HRMS, m/z: $373.1898\left([\mathrm{M}+\mathrm{H}]^{+}\right.$, calcd. for $\mathrm{C}_{22} \mathrm{H}_{23} \mathrm{~N}_{5} \mathrm{O}$ 373.1897). MS, $m / z(\%): 373\left([\mathrm{M}+\mathrm{H}]^{+}, 3\right), 357$ (13), 288 (13), 259 (15), 128 (12), 127 (21), 114 (15), 84 (100), 69 (28). $\mu_{\text {eff }} \sim 1.73 \mu_{\mathrm{B}}(50-300 \mathrm{~K})$. Anal. Calcd. for $\mathrm{C}_{22} \mathrm{H}_{22} \mathrm{~N}_{5} \mathrm{O}$ (372.45): C, 71.0; H, 6.0; N, 18.8. Found: C, 71.0; H, 5.9; N, 18.7 .

\section{4,4,5,5-Tetramethyl-2-(3-(4-ethylphenyl)-6-phenyl-1,2,4-triazin-5-yl)-4,5-dihydro-1H-} imidazol-3-oxide 1-oxyl (3b) and 4,4,5,5-tetramethyl-2-(3-(4-ethylphenyl)-6-diphenyl-1,2,4triazin-5-yl)-4,5-dihydro-1H-imidazol-1-oxyl (4b) were obtained by the procedure described for $3 \mathbf{a}$ and $\mathbf{4 a}$.

Compound (3b). Yield $124 \mathrm{mg}(30 \%)$, brown-red crystals, mp. $187-188{ }^{\circ} \mathrm{C}, R_{\mathrm{f}} 0.15\left(\mathrm{C}_{6} \mathrm{H}_{6}-\right.$ ethyl acetate, 9:1). IR: $v=2966,2933,1609,1579,1498,1448,1419,1394,1371,1215,1173$, 1136, 1117, 1079, 1053, 1016, 972, 874, 854, 812, 766, 748, 702, 673, 626, 541, 508, $476 \mathrm{~cm}^{-1}$. HRMS, $m / z$ : $416.2084\left(\mathrm{M}^{+}\right.$, calcd. for $\mathrm{C}_{24} \mathrm{H}_{26} \mathrm{~N}_{5} \mathrm{O}_{2}$ 416.2081). MS, $m / z(\%): 416\left(\mathrm{M}^{+}, 31\right), 385$ (23), 384 (14), 316 (14), 287 (30), 257 (13), 169 (17), 133 (23), 131 (16), 128 (26), 127 (27), 116 (24), 105 (11), 69 (51), 41 (18), 18 (21). $\mu_{\text {eff }} \sim 1.73 \mu_{\mathrm{B}}(50-300 \mathrm{~K})$. Anal. Calcd. for $\mathrm{C}_{24} \mathrm{H}_{26} \mathrm{~N}_{5} \mathrm{O}_{2}$ (416.50): C, 69.2; H, 6.3; N, 16.8. Found: C, 69.2; H, 6.8; N, 16.9.

Compound (4b). Yield $128 \mathrm{mg}(32 \%)$, bright-orange crystals, mp. $144-145{ }^{\circ} \mathrm{C}, R_{\mathrm{f}} 0.45\left(\mathrm{C}_{6} \mathrm{H}_{6}-\right.$ ethyl acetate, 9:1). IR: $v=2976,2933,1610,1522,1498,1444,1396,1280,1232,1183,1160$, $1141,1058,1017,865,823,801,767,700,618,560 \mathrm{~cm}^{-1}$. HRMS, $m / z: 401.2214\left([\mathrm{M}+\mathrm{H}]^{+}\right.$, 
calcd. for $\mathrm{C}_{24} \mathrm{H}_{27} \mathrm{~N}_{5} \mathrm{O}$ 401.2210). MS, $m / z$ (\%): 401 ([M+H] $\left.]^{+}, 10\right), 385$ (16), 384 (13), 316 (14), 288 (10), 287 (27), 286 (13), 169 (11), 131 (12), 128 (16), 127 (15), 116 (11), 114 (10), 84 (100), 69 (28), 41 (11), 28 (16). $\mu_{\text {eff }} \sim 1.73 \mu_{\mathrm{B}}(50-300 \mathrm{~K})$. Anal. Calcd. for $\mathrm{C}_{24} \mathrm{H}_{26} \mathrm{~N}_{5} \mathrm{O}$ (400.50): C, 72.0; H, 6.5; N, 17.5. Found: C, 71.8; H, 6.5; N, 17.6.

(E)-2-(2-(1H-Pyrazol-5-yl)vinyl)-4,4,5,5-tetramethyl-4,5-dihydro-1H-imidazol-3-oxide 1oxyl (6a), (E)-2-(2-(1-(methylcarbamoyl)-1H-pyrazol-3-yl)vinyl)-4,4,5,5-tetramethyl-4,5dihydro-1H-imidazol-3-oxide 1-oxyl (6b), 2-(2-ethynylcyclopropyl)-4,4,5,5-tetramethyl-4,5dihydro-1H-imidazol-3-oxide 1-oxyl (6c). To a stirred at $0{ }^{\circ} \mathrm{C}$ solution of enyne 2 (207 $\mathrm{mg}, 1.0$ mmol) in $\mathrm{Et}_{2} \mathrm{O}(30 \mathrm{ml})$ was added a solution of $\mathrm{CH}_{2} \mathrm{~N}_{2}$ in $\mathrm{Et}_{2} \mathrm{O}$ prepared following a standard method from $227 \mathrm{mg}$ ( $2.2 \mathrm{mmol}$ ) of $N$-methyl- $N$-nitroso urea. The cooling bath was removed; the reaction mixture was stirred for $24 \mathrm{~h}$ and concentrated in vacuo. The residue was purified on a column with $\mathrm{SiO}_{2}$ to give 6c ( $n$-hexane - EtOAc 6:4), 6b ( $n$-hexane - EtOAc 4:6) and 6a ( $n$ hexane - EtOAc 2:8). The fractions containing $\mathbf{6 a}, \mathbf{6 b}$, and $\mathbf{6 c}$ were concentrated at reduced pressure, the residues were crystallized from a mixture of $n$-heptane with $\mathrm{CH}_{2} \mathrm{Cl}_{2}$.

Compound (6a). Yield $77 \mathrm{mg}$ (31\%), green crystals, mp. $179-181{ }^{\circ} \mathrm{C}, R_{\mathrm{f}} 0.15$. (n-hexane - ethyl acetate 2:8). IR: $v=3211,3106,3032,2988,1627,1562,1451,1399,1374,1321,1256,1211$, $1166,1136,1105,1050,1027,985,921,894,873,803,758,610,542,451,419 \mathrm{~cm}^{-1}$. HRMS, $m / z$ : $249.1352\left(\mathrm{M}^{+}\right.$, calcd. for $\mathrm{C}_{12} \mathrm{H}_{17} \mathrm{~N}_{4} \mathrm{O}_{2}$ 249.1346). MS, $m / z(\%): 249\left(\mathrm{M}^{+}, 73\right), 121(10), 120$ (12), 114 (9), 84 (100), 69 (70), 56 (16), 55 (15), 41 (28), 39 (7), 18 (13). Anal. Calcd. for $\mathrm{C}_{12} \mathrm{H}_{17} \mathrm{~N}_{4} \mathrm{O}_{2}$ (249.29): C, 57.8; H, 6.9; N, 22.5. Found: C, 57.8; H, 6.6; N, 22.5.

Compound (6b). Yield $61 \mathrm{mg}\left(20 \%\right.$ ), blue-green crystals, mp. $181-183{ }^{\circ} \mathrm{C}, R_{\mathrm{f}} 0.20$ ( $n$-hexane EtOAc 4:6). IR: $v=3368,3107,3030,2987,2945,1709,1625,1520,1454,1419,1371,1361$, $1274,1253,1238,1213,1163,1138,1058,1030,977,962,873,809,767,754,660,538,450$, $422 \mathrm{~cm}^{-1} . \mu_{\text {eff }} \sim 1.73 \mu_{\mathrm{B}}(50-100 \mathrm{~K}) . \mathrm{C}_{14} \mathrm{H}_{20} \mathrm{~N}_{5} \mathrm{O}_{3}$ (306.34): calcd. C, 54.9; H, 6.6; N, 22.9; found C, 54.8; H, 7.0; N, 22.7. IR: $v=3368,3107,3030,2987,2945,1709,1625,1520,1454,1419$, 1371, 1361, 1274, 1253, 1238, 1213, 1163, 1138, 1058, 1030, 977, 962, 873, 809, 767, 754, 660, $538,450,422 \mathrm{~cm}^{-1} . \mu_{\text {eff }} \sim 1.73 \mu_{\mathrm{B}}(50-100 \mathrm{~K})$. Anal. Calcd. for $\mathrm{C}_{14} \mathrm{H}_{20} \mathrm{~N}_{5} \mathrm{O}_{3}$ (306.34): C, 54.9; H, 6.6; N, 22.9. Found: C, 54.8; H, 7.0; N, 22.7.

Compound (6c). Yield $73 \mathrm{mg}$ (33\%), violet oil, $R_{\mathrm{f}} 0.25$ ( $n$-hexane - ethyl acetate 6:4). IR: $v=$ 3237, 3092, 2983, 2928, 1536, 1454, 1399, 1371, 1348, 1283, 1216, 1178, 1138, 1116, 1071, 1027, 920, 867, 821, 709, 680, 618, 540, $477 \mathrm{~cm}^{-1}$. HRMS, m/z: $221.1285\left(\mathrm{M}^{+}\right.$, calcd. for $\mathrm{C}_{12} \mathrm{H}_{17} \mathrm{~N}_{2} \mathrm{O}_{2}$ 221.1290). MS, m/z (\%): $221\left(\mathrm{M}^{+}, 19\right), 114$ (15), 85 (7), 84 (100), 83 (13), 69 (67), 56 (12), 55 (18), 41 (32), 39 (10). Anal. Calcd. for $\mathrm{C}_{12} \mathrm{H}_{17} \mathrm{~N}_{2} \mathrm{O}_{2}$ (221.28): C, 65.1; H, 7.7; N, 12.7. Found: $\mathrm{C}, 65.1 ; \mathrm{H}, 7.7 ; \mathrm{N}, 12.7$.

(E)-2-(2-(3-(Ethoxycarbonyl)isoxazol-5-yl)vinyl)-4,4,5,5-tetramethyl-4,5-dihydro-1Himidazol-3-oxide 1-oxyl (8). To a stirred solution of enyne 5 (207 mg, $1.0 \mathrm{mmol})$ and ethyl 2chloro-2-(hydroxyimino)acetate $(227 \mathrm{mg}, 1.5 \mathrm{mmol})$ in dry $\mathrm{Et}_{2} \mathrm{O}(35 \mathrm{ml})$ a solution of $\mathrm{NEt}_{3}$ $(0.208 \mathrm{ml}, 1.5 \mathrm{mmol})$ in $\mathrm{Et}_{2} \mathrm{O}(30 \mathrm{ml})$ was added dropwise over the period of $1 \mathrm{hr}$ at $0{ }^{\circ} \mathrm{C}$ under argon atmosphere. The cooling bath was removed; the reaction mixture was stirred for $2 \mathrm{~h}$ and concentrated in vacuo. The obtained residue was put through a column with $\mathrm{SiO}_{2}$ using a mixture 
of hexane with ethyl acetate $(7: 3)$ as the eluent. The blue-green colored fraction was evaporated until dry under reduced pressure, the obtained residue was recrystallized from a mixture of $n$ heptane and $\mathrm{CH}_{2} \mathrm{Cl}_{2}$. Yield $200 \mathrm{mg}(62 \%)$, green crystals, mp. 107-108 ${ }^{\circ} \mathrm{C}, R_{\mathrm{f}} 0.15$ (hexane ethyl acetate 7:3). IR: $v=3142,3103,2986,2941,1746,1727,1571,1452,1416,1375,1275$, 1212, 1140, 1109, 1023, 980, 969, 834, 779, $542 \mathrm{~cm}^{-1}$. HRMS, $m / z: 322.1401\left(\mathrm{M}^{+}\right.$, calcd. for $\mathrm{C}_{15} \mathrm{H}_{20} \mathrm{~N}_{3} \mathrm{O}_{5}$ 322.1397). MS, $m / z(\%): 322\left(\mathrm{M}^{+}, 31\right), 161$ (7), 149 (10), 135 (8), 114 (9), 85 (8), 84 (100), 83 (8), 69 (45), 57 (10), 56 (12), 43 (8), 29 (11), 28 (30), 18 (19). $\mu_{\text {eff }} \sim 1.73 \mu_{\mathrm{B}}$ (50-300 K). Anal. Calcd. for $\mathrm{C}_{15} \mathrm{H}_{20} \mathrm{~N}_{3} \mathrm{O}_{5}$ (322.34): 55.9; H, 6.3; N, 13.0. Found: C, 55.7; H, 6.1; $\mathrm{N}, 12.8$.

\section{2-(3-(Ethoxycarbonyl)isoxazol-5-yl))-4,4,5,5-tetramethyl-4,5-dihydro-1 $H$-imidazol-3-oxide}

1-oxyl (11). To a stirred solution of 9 (170 $\mathrm{mg}, 0.94 \mathrm{mmol})$ and ethyl 2-chloro-2(hydroxyimino)acetate $(151 \mathrm{mg}, 1.0 \mathrm{mmol})$ in dry $\mathrm{Et}_{2} \mathrm{O}(15 \mathrm{ml}) \mathrm{NEt}_{3}(0.1 \mathrm{ml})$ was added at $0{ }^{\circ} \mathrm{C}$ under argon atmosphere. The cooling bath was removed; the reaction mixture was stirred for $4 \mathrm{~h}$ and concentrated in vacuo. The obtained residue was put through a column with $\mathrm{SiO}_{2}$ using ethyl acetate as the eluent. The blue-colored fraction was evaporated until dry under reduced pressure, the obtained residue was recrystallized from a mixture of $n$-heptane and $\mathrm{CH}_{2} \mathrm{Cl}_{2}$. Yield $140 \mathrm{mg}$ (50\%), blue needles, mp. $193-195{ }^{\circ} \mathrm{C}, R_{\mathrm{f}} 0.73$ (ethyl acetate). IR: $v=3177,2990,2942,1745$, $1599,1459,1383,1373,1256,1218,1196,1172,1137,1018,934,864,834,780,623 \mathrm{~cm}^{-1} . \mu_{\mathrm{eff}}$ $\sim 1.73 \mu_{\mathrm{B}}(30-300 \mathrm{~K})$. Anal. Calcd. for $\mathrm{C}_{13} \mathrm{H}_{18} \mathrm{~N}_{3} \mathrm{O}_{5}$ (296.30): 52.7; H, 6.1; N, 14.2. Found: C, $53.0 ; \mathrm{H}, 6.1 ; \mathrm{N}, 14.4$.

4,4,5,5-Tetramethyl-2-(1-(pyrrolidin-1-yl)but-3-ynyl)-4,5-dihydro-1H-imidazol-3-oxide 1oxyl (12). To a stirred solution of enyne $2(207 \mathrm{mg}, 1.0 \mathrm{mmol})$ in toluene $(20 \mathrm{ml})$ pyrrolidine $(0.15 \mathrm{ml}, 1.8 \mathrm{mmol})$ was added at $0{ }^{\circ} \mathrm{C}$. The reaction mixture was stirred at room temperature for $24 \mathrm{~h}$ and concentrated in vacuo. The obtained residue was put through a column with $\mathrm{SiO}_{2}$ using $\mathrm{Et}_{2} \mathrm{O}$ as the eluent. The crimson-colored fraction was evaporated until dry under reduced pressure; the obtained residue was recrystallized from $n$-heptane with filtration. Yield $72 \mathrm{mg}$ (26\%), crimson crystals, mp $97-98{ }^{\circ} \mathrm{C}, R_{\mathrm{f}} 0.20\left(\mathrm{Et}_{2} \mathrm{O}\right) . \mathrm{IR}: v=3242,2966,2875,2805,2102$, 1450, 1410, 1372, 1326, 1252, 1208, 1165, 1138, 933, 831, 725, 618, 541, 531, $461 \mathrm{~cm}^{-1}$. HRMS, $m / z: 278.1867\left(\mathrm{M}^{+}\right.$, calcd. for $\mathrm{C}_{15} \mathrm{H}_{24} \mathrm{~N}_{3} \mathrm{O}_{2}$ 278.1863). MS, $m / z(\%): 278\left(\mathrm{M}^{+}, 1\right), 261$ (2), 260 (2), 246 (3), 244 (4), 205 (2), 147 (2), 109 (7), 108 (100), 107 (4), 106 (6), 84 (3), 82 (2), 70 (2), 66 (4), 55 (4), 41 (4), 39 (2). Anal. Calcd. for $\mathrm{C}_{15} \mathrm{H}_{24} \mathrm{~N}_{3} \mathrm{O}_{2}$ (278.37): C, 64.7; H, 8.7; N, 15.1. Found: C, 64.7; H, 8.7; N, 15.1 .

2,2'-((1E,7E)-Octa-1,7-dien-3,5-diyne-1,8-diyl)bis(4,4,5,5-tetramethyl-4,5-dihydro-1Himidazol-3-oxide 1-oxyl) (13). Through a mixture of 5 (30 mg, $0.15 \mathrm{mmol}), \mathrm{CuCl}(2 \mathrm{mg}, 0.02$ $\mathrm{mmol}), N, N, N^{\prime}, N^{\prime}$-tetramethylethylene-1,2-diamine $(2 \mathrm{mg}, 0.02 \mathrm{mmol})$ and acetone $(3 \mathrm{ml})$ oxygen was bubbled at room temperature until 5 disappered (TLC control). The reaction mixture was diluted with $\mathrm{CHCl}_{3}(5 \mathrm{ml})$ and put onto a column with $\mathrm{SiO}_{2}(1.5 \times 15 \mathrm{~cm})$ wetted with $\mathrm{CHCl}_{3}$. The column was eluted with $\mathrm{CHCl}_{3}$. The yellow-green fraction was diluted with $n$ heptane $(5 \mathrm{ml})$ and evaporated in vacuo until residue formed which was filtered off and recrystallized from a mixture of ethyl acetate with $n$-heptane. Yield $15 \mathrm{mg}$ (50\%), bundles of thin 
yellow-green crystals, $R_{\mathrm{f}} 0.68$ (ethyl acetate); the crystals turn brown upon heating above 120 $125^{\circ} \mathrm{C}$. IR: $v=3053,2982,2938,2597,2353,2310,2180,1808,1581,1451,1432,1415,1387$, $1372,1308,1264,1243,1212,1165,1137,968,860,743,616,541,477,447,421 \mathrm{~cm}^{-1}$. UV/Vis $\left(\mathrm{CHCl}_{3}\right): \lambda_{\max }\left(\varepsilon, \mathrm{M}^{-1} \mathrm{~cm}^{-1}\right)=269$ (15000), 292 (14000), 330 sh. (23000), 346 (30000), 374 (37000), 403 (38000) nm. $\mu_{\text {eff }} \sim 2.45 \mu_{\mathrm{B}}(100-300 \mathrm{~K})$. Anal. Calcd. for $\mathrm{C}_{18} \mathrm{H}_{24} \mathrm{~N}_{4} \mathrm{O}_{4}(360.41): \mathrm{C}$, 64.1; H, 6.8; N, 13.6. Found: C, 63.8; H, 6.6; N, 13.5.

\section{X-Ray structure determinations}

Crystal data for compounds were collected on a Smart APEX CCD diffractometer using graphite-monochromated Mo-Ka $(\lambda=0.71073 \AA)$. The cell parameters were determined and refined by the least squares method for all reflections. The structures were solved by direct methods and refined by least squares procedures on $F^{2}$. All non-hydrogen atoms were refined anisotropically. Positions of all hydrogen atoms were calculated geometrically and refined as riding on the respective carbon-bonded atoms. All structure solution and refinement calculations were performed with Bruker Shelxtl Version 6.12. The worst situation was with 13, which forms very fine thread-like single crystals. As a result, we determined only the structure of the molecule, and only the unit cell parameters are given for this compound.

Compound (3a). $\mathrm{C}_{22.5} \mathrm{H}_{23} \mathrm{ClN}_{5} \mathrm{O}_{2} ; F W=430.90 ; \mathrm{T}=295 \mathrm{~K}$; Monoclinic, $P 2_{1} / n ; a=12.761(7), b$ $=10.899(6), c=15.916(8) \AA ; \beta=94.625(9)^{\circ} ; V=2206.4(19) \AA^{3} ; Z=4, D_{\mathrm{C}}=1.297 \mathrm{~g} / \mathrm{cm}^{3} ; \mu=$ $0.202 \mathrm{~mm}^{-1} ; 2.13<\theta<27.49^{\circ} ; 13767$ collected, 4942 unique, $R_{\text {int }}=0.0851 ; 339$ parameters; Goof $=0.808 ; R$ indices for $I>2 \sigma R_{1}=0.0529, w R_{2}=0.1202 ; R$ indices (all data) $R_{1}=0.1216, w R_{2}=$ 0.1440 .

Compound (4a). $\mathrm{C}_{22} \mathrm{H}_{22} \mathrm{~N}_{5} \mathrm{O} ; F W=372.45 ; \mathrm{T}=240 \mathrm{~K}$; Orthorhombic, Pbca; $a=14.6206(12), b$ $=14.6087(15), c=19.0240(12) \AA ; V=4063.3(6) \AA^{3} ; Z=8, D_{\mathrm{C}}=1.218 \mathrm{~g} / \mathrm{cm}^{3} ; \mu=0.078 \mathrm{~mm}^{-1}$; $2.14<\theta<28.34^{\circ} ; 18015$ collected, 4687 unique, $R_{\text {int }}=0.0759 ; 254$ parameters; Goof $=0.727 ; R$ indices for $I>2 \sigma R_{1}=0.0460, w R_{2}=0.1190 ; R$ indices (all data) $R_{1}=0.1379, w R_{2}=0.1597$.

Compound (3b). $\mathrm{C}_{24} \mathrm{H}_{26} \mathrm{~N}_{5} \mathrm{O} ; F W=400.5 ; \mathrm{T}=240 \mathrm{~K}$; Monoclinic, $P 2_{1} / n ; a=19.775(4), b=$ 11.672(2), $c=21.437(5) \AA ; \beta=115.348(12)^{\circ} ; V=4471.5(17) \AA^{3} ; Z=8, D_{\mathrm{C}}=1.190 \mathrm{~g} / \mathrm{cm}^{3} ; \mu=$ $0.076 \mathrm{~mm}^{-1} ; 2.04<\theta<28.46^{\circ} ; 33185$ collected, 10795 unique, $R_{\text {int }}=0.1145 ; 542$ parameters; Goof $=1.000 ; R$ indices for $I>2 \sigma R_{1}=0.0722, w R_{2}=0.2063 ; R$ indices (all data) $R_{1}=0.2703, w R_{2}=$ 0.2792 .

Compound (5). $\mathrm{C}_{11} \mathrm{H}_{15} \mathrm{~N}_{2} \mathrm{O}_{2} ; F W=207.25 ; \mathrm{T}=295 \mathrm{~K}$; Orthorhombic, Pna2 ${ }_{1} ; a=19.553(2), b=$ 9.1114(11), $c=13.6744(19) \AA ; \beta=109.277(11){ }^{\circ} ; V=2299.6(5) \AA^{3} ; Z=8, D_{\mathrm{C}}=1.197 \mathrm{~g} / \mathrm{cm}^{3} ; \mu$ $=0.084 \mathrm{~mm}^{-1} ; 2.75<\theta<26.38^{\circ} ; 9351$ collected, 2333 unique, $R_{\text {int }}=0.0521 ; 184$ parameters; Goof $=1.000 ; R$ indices for $I>2 \sigma R_{1}=0.0380, w R_{2}=0.0673 ; R$ indices (all data) $R_{1}=0.0739, w R_{2}=$ 0.0991 .

Compound (6a). $\mathrm{C}_{12} \mathrm{H}_{17} \mathrm{~N}_{4} \mathrm{O}_{2} ; F W=249.30 ; \mathrm{T}=295 \mathrm{~K}$; Monoclinic, $C 2 / c ; a=12.680(3), b=$ 9.066(2), $c=22.629(5) \AA ; V=2601.2(10) \AA^{3} ; Z=8, D_{\mathrm{C}}=1.273 \mathrm{~g} / \mathrm{cm}^{3} ; \mu=0.090 \mathrm{~mm}^{-1}$; $1.80<\theta<27.04^{\circ} ; 7408$ collected, 4017 unique, $R_{\text {int }}=0.0349 ; 333$ parameters; Goof $=0.877 ; R$ indices for $I>2 \sigma R_{1}=0.0537, w R_{2}=0.1244 ; R$ indices (all data) $R_{1}=0.0995, w R_{2}=0.1411$. 
Compound (6b). $\mathrm{C}_{14} \mathrm{H}_{21} \mathrm{~N}_{4} \mathrm{O}_{4} ; F W=309.35 ; \mathrm{T}=240 \mathrm{~K}$; Monoclinic, $P 2{ }_{1} / c ; a=10.2311(5), b=$ $10.1140(4), c=14.9675(7) \AA ; \beta=90.485(3)^{\circ} ; V=1548.74(12) \AA^{3} ; Z=4, D_{\mathrm{C}}=1.327 \mathrm{~g} / \mathrm{cm}^{3} ; \mu=$ $0.099 \mathrm{~mm}^{-1} ; 2.72<\theta<27.91^{\circ} ; 25066$ collected, 3688 unique, $R_{\text {int }}=0.0596 ; 280$ parameters; Goof $=0.717 ; R$ indices for $I>2 \sigma R_{1}=0.0390, w R_{2}=0.0943 ; R$ indices (all data) $R_{1}=0.0863, w R_{2}=$ 0.1132 .

Compound (11). $\mathrm{C}_{13} \mathrm{H}_{18} \mathrm{~N}_{3} \mathrm{O}_{5} ; F W=296.30 ; \mathrm{T}=240 \mathrm{~K}$; Monoclinic, $P 2_{1} / n ; a=7.178(3), b=$ $17.301(6), c=12.046(3) \AA ; \beta=98.32(2)^{\circ} ; V=1480.3(8) \AA^{3} ; Z=4, D_{\mathrm{C}}=1.330 \mathrm{~g} / \mathrm{cm}^{3} ; \mu=0.103$ $\mathrm{mm}^{-1} ; 2.07<\theta<28.42^{\circ} ; 11798$ collected, 3550 unique, $R_{\text {int }}=0.2119$; 191 parameters; Goof $=$ $0.946 ; R$ indices for $I>2 \sigma R_{1}=0.0590, w R_{2}=0.1142 ; R$ indices (all data) $R_{1}=0.0968, w R_{2}=$ 0.1636 .

Compound (13). $\mathrm{C}_{16} \mathrm{H}_{28} \mathrm{~N}_{4} \mathrm{O}_{4} ; F W=340.42 ; \mathrm{T}=173 \mathrm{~K}$; Monoclinic, $P 2{ }_{1} / n ; a=9.7117(18), b=$ 22.485(4), $c=10.447(2) \AA ; \beta=103.44^{\circ} ; V=2218.8(7) \AA^{3} ; Z=4, D_{\mathrm{C}}=1.019 \mathrm{~g} / \mathrm{cm}^{3}$.

Compound $\left[\left(\mathrm{Cu}(\mathrm{hfac})_{2}\right)_{3}(\mathbf{6 c})_{2}\right] \cdot \mathrm{C}_{7} \mathrm{H}_{16}: \mathrm{C}_{61} \mathrm{H}_{56} \mathrm{Cu}_{3} \mathrm{~F}_{36} \mathrm{~N}_{4} \mathrm{O}_{16} ; F W=1975.72 ; \mathrm{T}=240 \mathrm{~K}$; Triclinic, $P-1 ; a=11.4116(10), b=11.6299(10), c=16.8443(15) \AA \AA \alpha=107.298(4), \beta=98.428(4), \gamma=$ $106.055(3)^{\circ} ; V=1986.3(3) \AA^{3} ; Z=1, D_{\mathrm{C}}=1.652 \mathrm{~g} / \mathrm{cm}^{3} ; \mu=0.943 \mathrm{~mm}^{-1} ; 1.92<\theta<32.29^{\circ} ; 47428$ collected, 13446 unique, $R_{\text {int }}=0.0422 ; 682$ parameters; Goof $=0.941 ; R$ indices for $I>2 \sigma R_{1}=$ $0.0343, w R_{2}=0.0906 ; R$ indices (all data) $R_{1}=0.0609, w R_{2}=0.0976$.

\section{Magnetic measurements}

The magnetochemical measurements were performed on a MPMSXL SQUID magnetometer (Quantum Design) in the 2-300 K temperature range at a magnetic field strength $\mathrm{H}=5 \mathrm{kOe}$. The molar magnetic susceptibility $\chi$ was calculated taking into account the atomic diamagnetism according to the Pascal additive scheme. In the paramagnetic region, the effective magnetic moment was calculated from the equation $\mu_{\text {eff }}=\left[\left(3 \mathrm{k} / \mathrm{N}_{\mathrm{A}} \beta^{2}\right) \chi \mathrm{T}\right]^{1 / 2} \approx(8 \chi \mathrm{T})^{1 / 2}$, where $\mathrm{k}$ is the Boltzmann constant, $\mathrm{N}_{\mathrm{A}}$ is Avogadro's number and $\beta$ is the Bohr magneton.

\section{Supplementary Information}

Dependences of $\mu_{\mathrm{eff}}(T)$ for the nitroxides $\mathbf{3 a}, \mathbf{b}, \mathbf{4 a}, \mathbf{b}, \mathbf{5}, \mathbf{6 b}$ and $\mathbf{1 3}$, ESR spectra of $\mathbf{3 b}$ and $\mathbf{4 b}$ and the result of their modeling, molecular structures of 11 and $\left[\left(\mathrm{Cu}(\mathrm{hfac})_{2}\right)_{3}(\mathbf{6 c})_{2}\right] \cdot \mathrm{C}_{7} \mathrm{H}_{16}$ are available as Supporting Information.

Crystallographic data for compounds have been deposited with the Cambridge Crystallographic Data Centre: CCDC Nos. 781679 (11), 781680 (3a), 781681 (3b), 781682 (4a), 781683 (5), $781684(\mathbf{6 a}), 781685(\mathbf{6 b}), 802867\left(\left[\left(\mathrm{Cu}(\mathrm{hfac})_{2}\right)_{3}(\mathbf{6 c})_{2}\right] \cdot \mathrm{C}_{7} \mathrm{H}_{16}\right)$. This information can be obtained free of charge from The Director, CCDC, 12 Union Road, Cambridge, CB2 1EZ, UK (fax: +441223-336033; e-mail: deposit@ccdc.cam.ac.uk or http://www.ccdc.cam.ac.uk). 


\section{Acknowledgements}

The financial support by Russian Foundation for Basic Research (grants 09-03-00091, 09-0312108, 08-03-00025, 10-03-00756-a), U.S. Civilian Research and Development Foundation (REC-005), the Ministry of Science and Education (Grant for Leading Scientific Schools, Project NSh-65261.2010.3), Ural and Siberian Branches of the Russian Academy of Sciences is gratefully acknowledged.

\section{References}

1. Ullman, E. F.; Osiecki, J. H.; Boocock, D. G. B.; Darcy, R. J. Am. Chem. Soc. 1972, 94, 7049.

2. Tretyakov, E. V.; Ovcharenko V. I. Russ. Chem. Rev. 2009, 78, 971.

3. Boocock, D. G. B.; Darcy, R.; Ullman E. F. J. Am. Chem. Soc. 1968, 21, 5945.

4. (a) Leute, R. K.; Ullman, E. F. U.S. Patent 3697 535, 1972. (b) Weiss, R.; Kraut, N.; Hampel. F. J. Organomet. Chem. 2001, 617, 473. (c) Fokin, S. V.; Romanenko, G. V.; Baumgarten, M.; Ovcharenko, V. I. J. Struct. Chem. 2003, 44, 864.

5. (a) Ovcharenko, V. I.; Chupakhin, O. N.; Kovalev, I. S.; Tretyakov, E. V.; Romanenko, G. V.; Stass, D. V. Russ. Chem. Bull., Int. Ed. 2008, 57, 2227. (b) Chupakhin, O. N.; Utepova, I. A.; Varaksin, M. V.; Tretyakov, E. V.; Romanenko, G. V.; Stass, D. V.; Ovcharenko, V. I. J. Org. Chem. 2009, 74, 2870.

6. Chupakhin, O. N.; Charushin, V. N.; van der Plas, H. Nucleophilic Aromatic Substitution of Hydrogen; Academic Press: New York, San Diego, 1994; p. 367.

7. Makosza, M.; Wojciechowski, K. Chem. Rev. 2004, 104, 2631.

8. Okusa, G.; Kumagai, M.; Itai, T. Chem. Pharm. Bull. 1969, 17, 2502.

9. Igeta, H.; Tsuchiya, T.; Nakai, T. Tetrahedron Lett. 1969, 2667.

10. (a) Mitsuhashi, K.; Takayanagi, H.; Matsuno, S.; Tanaka, K. J. Heterocycl. Chem. 1982, 19, 1389. (b) Yang, J.; Gharagozloo, P.; Yao, J.; Ilyin, V. I.; Carter, R. B.; Nguyen, P.; Robledo, S.; Woodward, R. M.; Hogenkamp, D. J. J. Med. Chem. 2004, 47, 1547.

11. Werner, E. A. J. Chem. Soc. 1919, 115, 1093.

12. Campbell, M. M.; Coaford, N. D. P.; Rae, D. R.; Sainsbury, M. J. Chem. Soc., Perkin Trans. $11991,765$.

13. Tretyakov, E.; Romanenko, G.; Podoplelov, A.; Ovcharenko, V. Eur. J. Org. Chem. 2006, 2695.

14. (a) Tretyakov, E.; Romanenko, G.; Ikorskii, V.; Stass, D.; Vasiliev, V.; Demina, M.; Mareev, A.; Medvedeva, A.; Gorelik, E.; Ovcharenko, V. Eur. J. Org. Chem. 2007, 3639. (b) Tretyakov, E.; Tolstikov, S.; Mareev, A.; Medvedeva, A.; Romanenko, G.; Stass, D.; Bogomyakov, A.; Ovcharenko, V. Eur. J. Org. Chem. 2009, 2548.

15. Eglinton, G.; Galbraith, A. R. J. Chem. Soc. 1959, 889. 
16. Hay, A. S. J. Org. Chem. 1962, 27, 3320.

17. Org. Synth. 1993; Coll. Vol. 8, 63. Org. Synth. 1987, 65, 52.

18. Allen, F. H.; Kennard, O.; Watson, D. G.; Brammer, L.; Orpen, A. G.; Taylor, R. J. Chem. Soc., Perkin Trans. 2 1987, S1.

19. Bleaney, B.; Bowers, K. D. Proc. Roy. Soc. 1952, A214, 451.

20. Ginsberg, A. P.; Lines, M. E. Inorg. Chem. 1972, 11, 2289.

21. (a) Bolton, J. R.; Carrington, A. Mol. Phys. 1962, 5, 161. (b) Freed, J. H.; Fraenkel, G. K. J. Chem. Phys. 1962, 37, 1156.

22. Yamanaka, H.; Sakamoto, T.; Niitsuma, S. Heterocycles 1990, 31, 923.

23. (a) Ovcharenko, V. I.; Fokin, S. V.; Korobkov, I. V.; Rey P. Russ. Chem. Bull. 1999, 48, 1519 (Engl. Transl.). (b) Hirel, C.; Vostrikova, K. E.; Pecaut, J.; Ovcharenko, V. I.; Rey. P. Chem. Eur. J. 2001, 7, 2007.

24. Edwards, L.; Slassi, A.; Isaac, M.; McLeod, D. U.S. Patent 20070037 820, 2007.

25. Sviridenko, F. B.; Stass, D. V.; Kobzeva, T. V.; Tretyakov, E. V.; Klyatskaya, S. V.; Mshvidobadze, E. V.; Vasilevsky, S. F.; Molin, Yu. N. J. Am. Chem. Soc. 2004, 126, 2807.

26. Bennett, G. B. U.S. Patent 3963 713, 1976.

27. (a) Atkinson, C. M.; Cossey H. D. J. Chem. Soc. I962, 1805. (b) Saraswathi, T. V.; Srinivasan, V. R. Tetrahedron 1977, 33, 1043. 